\title{
Sensitivity of ozone dry deposition to ecosystem-atmosphere interactions: A critical appraisal of observations and simulations
}

Lin, Meiyun; Malyshev, Sergey; Shevliakova, Elena; Paulot, Fabien; Horowitz, Larry W.; Fares, Silvano; Mikkelsen, Teis Nørgaard; Zhang, Leiming

\section{Published in:}

Global Biogeochemical Cycles

Link to article, DOI:

10.1029/2018GB006157

Publication date:

2019

Document Version

Peer reviewed version

Link back to DTU Orbit

Citation (APA):

Lin, M., Malyshev, S., Shevliakova, E., Paulot, F., Horowitz, L. W., Fares, S., Mikkelsen, T. N., \& Zhang, L. (2019). Sensitivity of ozone dry deposition to ecosystem-atmosphere interactions: A critical appraisal of observations and simulations. Global Biogeochemical Cycles, 33(10), 1264-1288.

https://doi.org/10.1029/2018GB006157

\section{General rights}

Copyright and moral rights for the publications made accessible in the public portal are retained by the authors and/or other copyright owners and it is a condition of accessing publications that users recognise and abide by the legal requirements associated with these rights.

- Users may download and print one copy of any publication from the public portal for the purpose of private study or research.

- You may not further distribute the material or use it for any profit-making activity or commercial gain

- You may freely distribute the URL identifying the publication in the public portal 
Lin Meiyun (Orcid ID: 0000-0003-3852-3491)

Malyshev Sergey (Orcid ID: 0000-0001-6259-1043)

Paulot Fabien (Orcid ID: 0000-0001-7534-4922)

Horowitz Larry W. (Orcid ID: 0000-0002-5886-3314)

Fares Silvano (Orcid ID: 0000-0002-1990-0928)

Mikkelsen Teis N. (Orcid ID: 0000-0001-7470-6522)

Zhang Leiming (Orcid ID: 0000-0001-5437-5412)

Sensitivity of ozone dry deposition to ecosystem-atmosphere interactions: A critical appraisal of observations and simulations

Meiyun Lin ${ }^{1,2^{*}}$, Sergey Malyshev ${ }^{2}$, Elena Shevliakova ${ }^{2}$, Fabien Paulot ${ }^{1,2}$, Larry W.

Horowitz ${ }^{2}$, Silvano Fares ${ }^{3}$, Teis N. Mikkelsen ${ }^{4}$, Leiming Zhang ${ }^{5}$

* Corresponding author: Meiyun.Lin@noaa.gov (Tel: 1-609-452-6551)

${ }^{1}$ Program in Atmospheric and Oceanic Sciences, Princeton University, Princeton, NJ 08540, USA

${ }^{2}$ NOAA Geophysical Fluid Dynamics Laboratory, Princeton, NJ 08540, USA

${ }^{3}$ Council for Agricultural Research and Economics, Research Centre for Forestry and Wood,

Rome, Italy

${ }^{4}$ Department of Environmental Engineering, Technical University of Denmark, $2800 \mathrm{Kgs}$.

Lyngby, Denmark

${ }^{5}$ Air Quality Research Division, Science and Technology Branch, Environment and Climate Change Canada, Toronto, Canada

Submitted to Global Biogeochemical Cycles, December 12, 2018

Key Points:

- Observational analysis reveals drought stress causing 50\% reduction of ozone deposition velocities.

- Ecosystem-atmosphere interactions affect seasonal and interannual variability of ozone deposition.

- Dynamic vegetation land models with an interactive dry deposition scheme may provide mechanistic insights.

Abstract. The response of ozone $\left(\mathrm{O}_{3}\right)$ dry deposition to ecosystem-atmosphere interactions is poorly understood but is central to determining the potential for extreme pollution events under current and future climate conditions. Using observations and an interactive dry deposition scheme within two dynamic vegetation land models (GFDL LM3.0/LM4.0) driven by observation-based meteorological forcings over 1948-2014, we investigate the factors controlling seasonal and interannual variability (IAV) in $\mathrm{O}_{3}$ deposition velocities $\left(\mathrm{V}_{\mathrm{d}, \mathrm{O} 3}\right)$. Stomatal activity in this scheme is determined mechanistically, depending on phenology, soil moisture, vapor pressure deficit, and $\mathrm{CO}_{2}$ concentration. Soil moisture plays a key role in modulating the observed and simulated $\mathrm{V}_{\mathrm{d}, \mathrm{O} 3}$ seasonal changes over evergreen forests in Mediterranean Europe, South Asia, and the Amazon. Analysis of multi-year observations at This article has been accepted for publication and undergone full peer review but has not been through the copyediting, typesetting, pagination and proofreading process which may lead to differences between this version and the Version of Record. Please cite this article as doi: $10.1029 / 2018 \mathrm{~GB} 006157$ 
forest sites in Europe and North America reveals drought stress to reduce $\mathrm{V}_{\mathrm{d}, \mathrm{O} 3}$ by $\sim 50 \%$. Both LM3.0 and LM4.0 capture the observed $\mathrm{V}_{\mathrm{d}, \mathrm{O} 3}$ decreases due to drought; however, IAV is weaker by a factor of two in LM3.0 coupled to atmospheric models, particularly in regions with large precipitation biases. IAV in summertime $\mathrm{V}_{\mathrm{d}, \mathrm{O} 3}$ to forests, driven primarily by the stomatal pathway, is largest (15-35\%) in semi-arid regions of western Europe, eastern North America, and northeastern China. Monthly mean $\mathrm{V}_{\mathrm{d}, \mathrm{O} 3}$ for the highest year is two to four times that of the lowest, with significant implications for surface $\mathrm{O}_{3}$ variability and extreme events. Using $\mathrm{V}_{\mathrm{d}, \mathrm{O} 3}$ from LM4.0 in an atmospheric chemistry model improves the simulation of surface $\mathrm{O}_{3}$ abundance and spatial variability (reduces mean biases by $\sim 10 \mathrm{ppb}$ ) relative to the widely-used Wesely scheme.

Keywords: Ecosystem-atmosphere interactions; drought; ozone deposition; air quality; stomatal conductance

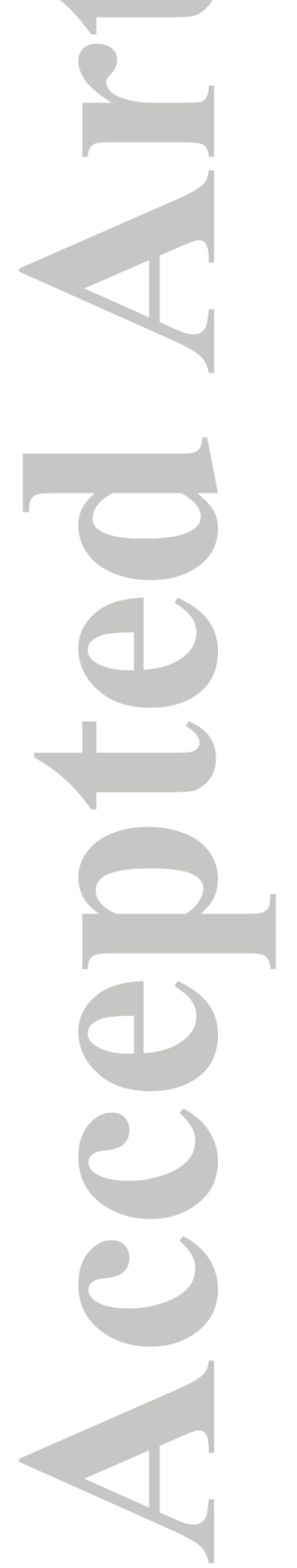




\section{Introduction}

Tropospheric ozone $\left(\mathrm{O}_{3}\right)$ is a potent greenhouse gas and biological oxidant detrimental to human health and vegetation, and is central to the atmospheric chemistry controlling the removal of numerous hazardous trace gases. Dry deposition to the Earth's surface accounts for $20 \%$ of the annual global tropospheric $\mathrm{O}_{3}$ loss according to atmospheric chemistry model estimates (Stevenson et al., 2006; Young et al., 2013). Dry deposition varies substantially across land types and ecosystems (Wesely, 1989) and represents an important control on near-surface $\mathrm{O}_{3}$ concentrations (Wild, 2007). Over many parts of the world, land-atmosphere interactions can modulate the dynamics of regional climate and ecosystem functioning (e.g., Seneviratne et al., 2006). The response of $\mathrm{O}_{3}$ dry deposition to ecosystem-atmosphere interactions is poorly understood, owing to a lack of reliable long-term observations and process-based model formulations (Fowler et al., 2009; Wu et al., 2018), but may influence extreme pollution events and susceptibility to climate change (Gerosa et al., 2009b; Andersson \& Engardt, 2010; Emberson et al., 2013; Lin et al., 2017). Here we systematically investigate the factors controlling the seasonal and interannual variability in $\mathrm{O}_{3}$ deposition velocities $\left(\mathrm{V}_{\mathrm{d}, \mathrm{O} 3}\right)$, using a suite of observations and dynamic vegetation land model hindcast simulations (1948-2014) including a new interactive dry deposition scheme.

Turbulence above a vegetation canopy facilitates contact between ambient $\mathrm{O}_{3}$ and vegetation, but the dominant control on the daytime $\mathrm{O}_{3}$ sink strength is usually the canopy resistance (Pilegaard et al., 1995; Mikkelsen et al., 2004; Wu et al., 2018), which has stomatal and nonstomatal components (Ganzeveld et al., 2015). Stomata, small pores in the leaf, are responsible for controlling $\mathrm{CO}_{2}$ transport for photosynthesis and water vapor losses; they also permit the uptake of $\mathrm{O}_{3}$ and other pollutants by vegetation. The stomatal uptake of $\mathrm{O}_{3}$ is largely regulated by the physiological activity and associated gas exchanges of the vegetation, with light, temperature, and water availability in the plant-soil system as the dominant controlling factors (Fowler et al., 2009). Under drought stress, plants close their stomata to conserve water, consequently limiting the $\mathrm{O}_{3}$ uptake by vegetation, affecting the observed seasonal cycle and interannual variability in daytime $\mathrm{V}_{\mathrm{d}, \mathrm{O} 3}$ (Matsuda et al., 2006; Rummel et al., 2007; Gerosa et al., 2009a; Gerosa et al., 2009b; Fares et al., 2014). There is also observational evidence that rising atmospheric $\mathrm{CO}_{2}$ concentrations cause stomatal conductance to decrease (Long et al., 2004; Lammertsma et al., 2011). Field work suggests that non-stomatal $\mathrm{O}_{3}$ sinks (including chemical reactions in the canopy air and deposition to plant and soil surfaces) are not constant, but vary with environmental variables, such as surface temperature, humidity, canopy wetness, friction velocity, and biogenic volatile organic compounds (BVOCs) or nitrogen oxides $\left(\mathrm{NO}_{\mathrm{x}}\right.$ ) in canopy air (Zhang et al., 2002; Coyle et al., 2009; Fares et al., 2010; Stella et al., 2011; El-Madany et al., 2017). More recently, Clifton et al. (2019) reported that suppression of soil uptake when soil is wet may explain observed interannual variability in $\mathrm{V}_{\mathrm{d}, \mathrm{O} 3}$ over a deciduous forest.

Current large-scale chemical transport models (CTMs) (Kukkonen et al., 2012; Hardacre et al., 2015; Morgenstern et al., 2017) typically include a variant of the Wesely (1989) parameterization ("the Wesely scheme") to calculate dry deposition. With a resistance-inseries framework, the Wesely scheme is well suited for inclusions in global models and has success in some applications when evaluating observed and modelled monthly mean climatology of $\mathrm{V}_{\mathrm{d}, \mathrm{O} 3}$ averaged globally across sites for a particular land cover type (Wesely \& Hicks, 2000; Val Martin et al., 2014; Silva \& Heald, 2018). However, the substantial interannual variability and site-to-site differences in $\mathrm{V}_{\mathrm{d}, \mathrm{O} 3}$ derived from measurements are not simulated by CTMs with the Wesely scheme driven by observed meteorology (Clifton et al., 
2017; Silva \& Heald, 2018). The expression for stomatal resistance used in the Wesely scheme is dependent on only solar radiation, air temperature, and leaf area index (LAI) (Wesely, 1989; Kavassalis \& Murphy, 2017). The lack of sensitivity to water availability is problematic: e.g., the Wesely scheme fails to simulate the observed $\mathrm{V}_{\mathrm{d}, \mathrm{O} 3}$ decreases over a Mediterranean forest during the August 2003 European drought (Rydsaa et al., 2016). CTMs not accounting for the effect of water availability on $\mathrm{O}_{3}$ stomatal deposition typically underestimate the highest observed surface $\mathrm{O}_{3}$ levels during severe drought events (Lin et al., 2017).

The non-stomatal deposition schemes as implemented in many models do not vary with meteorology, aside from some parameters prescribed for each season and each land cover, thereby missing many processes that can affect this deposition pathway, as suggested by field measurements (Fowler et al., 2009; Fares et al., 2010; Rannik et al., 2012; Clifton et al., 2019). Based on analysis of $\mathrm{O}_{3}$ flux measurements at five sites in North America, Zhang et al. (2003) developed a new scheme that parameterized non-stomatal resistance as a function of friction velocity, relative humidity, LAI, and canopy wetness ("the Zhang scheme"). Although these developments were applied in some regional models (Kukkonen et al., 2012), they have not generally been implemented in global-scale CTMs. Furthermore, these models typically do not include the influence of in-canopy chemistry, through which $\mathrm{O}_{3}$ may be scavenged by reactive BVOCs or $\mathrm{NO}_{\mathrm{x}}$ (Fares et al., 2010).

A few more recent regional CTMs (Simpson et al., 2012; Emberson et al., 2013; Huang et al., 2016) do parameterize the effect of soil moisture on stomatal conductance, following Jarvis (1976) in assuming that environmental factors act independently in determining stomatal conductance. In reality, the stomatal response to individual variables are complex and usually non-linear (Leuning, 1995). Some global land-carbon cycle models include the effects of $\mathrm{O}_{3}$ exposure on photosynthesis and stomatal conductance (Sitch et al., 2007; Lombardozzi et al., 2015). Val Martin et al. (2014) showed that coupling to vegetation phenology improved the simulation of $\mathrm{V}_{\mathrm{d}, \mathrm{O} 3}$ seasonality in a chemistry-climate model. The $\mathrm{O}_{3}$ stomatal deposition in their model was based on the Ball-Berry conductance scheme, which does not account for stomatal closure under soil drying. Importantly, process-oriented evaluation of observed and simulated $\mathrm{V}_{\mathrm{d}, \mathrm{O} 3}$ interannual variability at sites around the globe is lacking in the published literature.

Advancing knowledge concerning sources of $\mathrm{V}_{\mathrm{d}, \mathrm{O} 3}$ variability on daily to multi-decadal time scales, particularly responses to ecosystem-atmosphere interactions and the feedbacks on surface air quality, requires that process-based, rather than empirical, dry deposition parameterizations be implemented in chemistry-climate models. In this work, we apply the new interactive dry deposition scheme of Paulot et al. (2018) to represent $\mathrm{O}_{3}$ deposition in NOAA's Geophysical Fluid Dynamics Laboratory (GFDL) dynamic vegetation land models (LM3.0/LM4.0) (Shevliakova et al., 2009; Milly et al., 2014; Zhao et al., 2018b; a), driven by observed atmospheric forcings (Sheffield et al., 2006) or coupled to NOAA's GFDL atmospheric chemistry-climate models (AM3/AM4) (Donner et al., 2011; Zhao et al., 2018b). Incorporated into a combined stomatal-photosynthesis model, this scheme mechanistically describes the response of stomatal conductance to phenology, $\mathrm{CO}_{2}$ concentration, temperature, canopy air vapor pressure deficit, and soil water availability. We analyze a suite of observations alongside the model simulations for the past half-century to assess the underlying processes controlling $\mathrm{O}_{3}$ deposition across the globe. Specifically, our analyses focus on examining the influence of regional and local environmental variables (e.g., drought stress) on $\mathrm{V}_{\mathrm{d}, \mathrm{O} 3}$ variability on seasonal to interannual time scales. 
Section 2 briefly describes $\mathrm{V}_{\mathrm{d}, \mathrm{O} 3}$ observations, model formulations, and experiments. We begin our analysis by investigating factors controlling the seasonal cycle of $\mathrm{V}_{\mathrm{d}, \mathrm{O} 3}$, including the spatial distributions of vegetation types, critical leaf temperature, and water availability (Section 3). We then use observations and model simulations to examine interannual variability of $\mathrm{V}_{\mathrm{d}, \mathrm{O} 3}$ during the growing season and the relationship of $\mathrm{V}_{\mathrm{d}, \mathrm{O} 3}$ to drought and precipitation (Section 4). Section 5 summarizes the global-to-regional distributions of $\mathrm{O}_{3}$ deposition to the major land cover classes, quantifies the contributions of stomatal versus non-stomatal pathways, identifies the regions in the world with the largest interannual variability in $\mathrm{V}_{\mathrm{d}, \mathrm{O} 3}$, and draws implications concerning the deployment of future measurements. In Section 6, we examine the influence on surface $\mathrm{O}_{3}$ simulations from the shift of $\mathrm{V}_{\mathrm{d}, \mathrm{O} 3}$ from the Wesely scheme to the new scheme as implemented in GFDL LM4.0. Specifically, we leverage the Tropospheric Ozone Assessment Report (TOAR) Surface Ozone Database with vast spatial coverage around the world (Schultz et al., 2017) and a new dataset over China (https://www.aqistudy.cn) to assess the two deposition schemes. Finally, we synthesize in Section 7 the model strengths and limitations, discuss the implications, and make recommendations for future $\mathrm{O}_{3}$ flux measurements.

\section{Methods}

\subsection{Ozone dry deposition observations}

We compile a suite of field-based $\mathrm{V}_{\mathrm{d}, \mathrm{O} 3}$ observations at 41 locations, obtained from 26 literature sources published between 1990 and 2018 (Table 1). Model evaluations are conducted on a site-by-site basis for the purpose of examining the influence from regional to local meteorology and land cover. Sites with continuous measurements for at least two years are used to evaluate the seasonal cycle of $\mathrm{V}_{\mathrm{d}, \mathrm{O} 3}$ (Section 3). To explore the influence of water availability on $\mathrm{V}_{\mathrm{d}, \mathrm{O} 3}$ seasonality, observations are separated into the dry and wet season for evergreen forest sites in Mediterranean Europe (Castelporziano, Italy), South Asia (Mea Moh and Datum Valley), and the Amazon. Multi-year measurements at a boreal forest in Denmark (1996-2000) and a deciduous forest in Ontario Canada (2008-2013) are analyzed for the influence of drought stress on $\mathrm{V}_{\mathrm{d}, \mathrm{O} 3}$ interannual variability (Section 4). For short-term observations, we focus on daytime average (9am-3pm) for the growing season (June-JulyAugust) to evaluate the modeled spatial variability of $\mathrm{V}_{\mathrm{d}, \mathrm{O} 3}$ across North America and Europe (Section 5). For comparison with observations, we sample modeled $\mathrm{V}_{\mathrm{d}, \mathrm{O} 3}$ to the land-cover tile that best matches the observed vegetation type at individual sites (as opposed to using a grid-cell average). Given the heterogeneity of land surface properties and the uncertainty in both the land model forcing dataset and $\mathrm{O}_{3}$ flux measurements themselves at finer temporal scales (i.e., daily to weekly), we focus on evaluating the most salient processes influencing seasonal to interannual variability in $\mathrm{V}_{\mathrm{d}, \mathrm{O} 3}$.

\subsection{Model formulations and experiments}

Paulot et al. (2018) developed an interactive dry deposition scheme in GFDL LM3.0 and evaluated the dry deposition velocities and fluxes of reactive nitrogen species. Here we evaluate and improve the dry deposition scheme for $\mathrm{O}_{3}$ in LM3.0 and an updated version of the land model, LM4.0. LM4.0 is a new model of terrestrial water, energy, and carbon, intended for use in global hydrological analyses and as a component of GFDL earth system and physical climate models contributing to the Coupled Model Intercomparison Project, Phase 6 (CMIP6) (Zhao et al., 2018a; b). Both LM3.0 and LM4.0 include five vegetation 
types (C3 and $\mathrm{C} 4$ grasses, and temperate deciduous, tropical and cold evergreen trees) and describe small-scale heterogeneity of land surface cover in each grid cell using a mosaic approach, as a combination of sub-grid tiles in four land use categories: lands undisturbed by human activity (i.e., "primary" or "natural"), cropland, pasture, and lands harvested at least once (i.e., "secondary"), including managed forests and abandoned croplands and pastures (Shevliakova et al., 2009; Malyshev et al., 2015). Planting and harvesting dates for crops as well as pasture grazing are updated as described by Paulot et al. (2018). Neither of the land model configurations used in this study includes treatment of irrigation or of nitrogen limitation on plant growth.

LM3.0 uses a $2^{\circ}$ latitude $\times 2.5^{\circ}$ longitude grid and is configured similarly to the land component of GFDL ESM2Mb (Dunne et al., 2012; Malyshev et al., 2015), except for the updates on cropping dates and pasture grazing. LM4.0 employs a cubed-sphere grid resolution of $\sim 100 \times 100 \mathrm{~km}^{2}$ and serves as the land component for the new set of GFDL AM4/CM4 models (Zhao et al., 2018a; b). Motivated by biases in LM3.0 simulations, the standard version of LM4.0 includes the following updates: (1) decreasing the cold season length threshold to better locate the cold evergreen-temperate deciduous forest boundary; (2) decreasing critical leaf temperature to better match the seasonal green-up as inferred from MODIS reflectances; (3) using a more physically based approach for drought-induced leaf drop; (4) changing soil types and parameters affecting surface albedo, plant hydraulics and biogeography (see Section 10 in Zhao et al., 2018a); (5) limiting the maximum LAI attainable by the vegetation on the basis of light availability. The aforementioned updates (1) to (3) follow parameterizations previously implemented in LM3.1, as described by Milly et al. (2014). In the LM4.0 experiments used in this study, soil types and soil parameter values were switched back to those used in LM3.0, which we find better simulate the observed sensitivity of $\mathrm{V}_{\mathrm{d}, \mathrm{O} 3}$ to drought (not shown). In Section 3, we evaluate how the changes in vegetation properties from LM3.0 to LM4.0 influence simulated $\mathrm{V}_{\mathrm{d}, \mathrm{O} 3}$.

Ozone deposition in the models is parameterized with a resistance-in-series approach:

$V_{d, O 3}=\left(R_{a}+R_{b}+R_{c}\right)^{-1}$

The parameterizations of aerodynamic $\left(R_{a}\right)$ and quasi-laminar resistances $\left(R_{b}\right)$ are described in detail by Paulot et al. (2018). The canopy conductance $\left(R_{c}^{-1}\right)$ includes non-stomatal and stomatal contributions. Non-stomatal resistance for $\mathrm{O}_{3}$, which includes in-canopy aerodynamic, cuticular, stem, and ground resistances, is parameterized as a function of friction velocity, LAI, and canopy wetness (Zhang et al., 2003; Paulot et al., 2018). In this study, the input parameters for non-stomatal deposition are modified to simulate more realistic $\mathrm{V}_{\mathrm{d}, \mathrm{O} 3}$ and surface $\mathrm{O}_{3}$ over snow-cover landscapes and under cold temperatures (see Supplemental Text S1 and Figs. S1-S2). For stomatal deposition, we incorporate leaf physiology by combining models of stomatal behavior and photosynthesis, as an alternative approach to modelling stomatal behavior only in terms of physical variables with a Javis (1976) type function. The equations for photosynthesis and stomatal conductance are described in detail in Appendices B3 and B4 of Weng et al. (2015), and are briefly summarized here.

Non-water limited stomatal conductance $\bar{g}_{s} \quad\left(\mathrm{~mol} \mathrm{H} \mathrm{H}_{2} \mathrm{O} \mathrm{m} \mathrm{m}^{-2} \mathrm{~s}^{-1}\right)$ averaged over the entire canopy depth is calculated as: 
$\bar{g}_{s}=\max \left(\frac{m \bar{A}_{n}}{\left(C_{i}-\Gamma_{*}\right)\left(1+D_{s} / D_{0}\right)}, g_{s, \min }\right)$

Where $\bar{A}_{n}$ is the net photosynthesis rate $\left(\mathrm{mol} \mathrm{CO} \mathrm{Cm}^{-2} \mathrm{~s}^{-1}\right)$ for a well-watered plant averaged over the entire canopy depth, $m$ is an empirical coefficient which represents the speciesspecific sensitivity of stomatal conductance to photosynthesis, $D_{s}$ is canopy air water vapor deficit $\left(\mathrm{kg} \mathrm{H}_{2} \mathrm{O} \mathrm{kg}{ }^{-1}\right.$ air, $D_{0}$ is a reference value), $C_{i}$ is intercellular concentration of $\mathrm{CO}_{2}$ (mol CO $\mathrm{mol}^{-1}$ air), $\Gamma_{*}$ is the $\mathrm{CO}_{2}$ compensation point $\left(\mathrm{mol} \mathrm{CO}_{2} \mathrm{~mol}^{-1}\right.$ air), and $g_{s, \text { min }}=$ $0.01 \mathrm{~mol} \mathrm{H}_{2} \mathrm{O} \mathrm{m}^{-2} \mathrm{~s}^{-1}$ is the minimum stomatal conductance for water vapor allowed in the model. Increasing atmospheric water vapor deficits and $\mathrm{CO}_{2}$ concentrations both cause $\bar{g}_{s}$ to decrease. A thermal inhibition factor $f(T)$ is applied to photosynthesis, affecting carbon acquisition and respiration equally:

$f(T)=\left(1+e^{0.4\left(T_{1}-T_{v}\right)}\right)^{-1}\left(1+e^{0.4\left(T_{v}-T_{2}\right)}\right)^{-1}$

Where $T_{v}$ is leaf temperature, and $T_{1}=5^{\circ} \mathrm{C}, T_{2}=45^{\circ} \mathrm{C}$. This factor causes stomatal conductance to decrease rapidly when temperature is outside of the $\left[T_{1}, T_{2}\right]$ range.

After the non-water limited photosynthesis and stomatal conductance are determined, the model applies corrections to account for limitations imposed by soil water availability $\left(\psi_{w}\right)$ and by canopy wetness $\left(\psi_{i}\right)$ :

$\overline{\overline{g_{s}}}=\psi_{w} \psi_{i} \overline{g_{s}}$

$\psi_{w}=\min \left(U_{\max } / U_{d}, 1\right)$

where $U_{\max }$ is the maximum plant water uptake rate ("water supply"), defined as the uptake rate when root water potential is at the plant permanent wilting point; $U_{d}$ is "water demand", calculated as transpiration rate at non-water limited stomatal conductance. Calculation of vegetation water uptake (Milly et al., 2014; Weng et al., 2015) takes into account the vertical distribution of soil water, the vertical distribution of fine roots, and their biomass simulated by the LM3.0/LM4.0 vegetation dynamics (Shevliakova et al., 2009). In each soil layer, roots are represented as cylinders of small radius, and the difference between bulk water potential of the soil and water potential at the soil-root interface for this layer is determined by the near-field steady-state solution of the flow equation (Gardner, 1960), with xylem of the plantroot system providing the connection across layers (Weng et al., 2015).

Downregulation of photosynthesis due to water interception is

$\psi_{i}=1-\left(f_{s}+f_{l}\right) \alpha_{w e t}$

where $f_{s}$ and $f_{l}$ are the fractions of canopy covered by snow and liquid water, respectively; $\alpha_{w e t}$ is the down-regulation coefficient, assumed to be 0.3 (i.e., photosynthesis of leaves fully covered by water or snow is reduced by $30 \%$ compared to dry leaves).

We conduct a suite of approximately 600-yr simulations with LM3.0 and LM4.0. The experiments consist of a 300-yr potential vegetation spin-up phase (undisturbed by human activity), an intermediate land-use spin-up phase (1700-1860), and a historical phase (18612014) with varying $\mathrm{CO}_{2}$ and land use (See Text S2). The dry deposition simulations are 
initialized from the 1948 conditions in the historical phase and continue through 2014, driven by observation-based meteorological forcings (Sheffield et al., 2006) (3-hourly precipitation, humidity, pressure, downward short and longwave radiation, near-surface temperatures and winds; available at http://hydrology.princeton.edu/data.php). These standalone land model hindcast simulations driven by observationally-based atmospheric forcings (here after "LM3.0" or "LM4.0") allow us to first investigate uncertainties in $\mathrm{V}_{\mathrm{d}, \mathrm{O} 3}$ parameterizations. Then we couple the land model to an atmospheric model ("AM3_LM3"; starting from the same 1948 initial land conditions as in LM3.0) to investigate the influence on simulated $\mathrm{V}_{\mathrm{d}, \mathrm{O} 3}$ from uncertainties in model atmospheric forcings, particularly precipitation (Section 4). To examine the influence of changes in $\mathrm{V}_{\mathrm{d}, \mathrm{O} 3}$ on surface $\mathrm{O}_{3}$, we also conduct a simulation with a prototype version of the new GFDL AM4 chemistry-climate model using prescribed $\mathrm{V}_{\mathrm{d}, \mathrm{O} 3}$ archived hourly from the standalone LM4.0 simulation (“AM4_LM4dd"; Section 6).

\section{Factors controlling seasonal cycle of ozone deposition velocity}

In this section, we discuss the simulation of vegetation properties that strongly influence the seasonality of $\mathrm{O}_{3}$ dry deposition. We discuss relevant improvements in the parameterization of these properties from LM3.0 to LM4.0 and show how these changes improve the simulation of $\mathrm{V}_{\mathrm{d}, \mathrm{O} 3}$.

\subsection{Distribution of vegetation types}

Figure 1 shows comparisons of June-July-August (JJA) average LAI for natural forests in LM3.0, LM4.0, and field-based measurements. The observational data set is a compilation of field-observed data for woody species at 1,216 locations, obtained from 554 literature sources published between 1932 and 2011 (Iio \& Ito, 2014). LM4.0 better simulates the LAI values for cold evergreen forest, deciduous forest, and tropical forest, while LM3.0 overestimates the field-based data, particularly for the deciduous and tropical forests. The improved simulation of LAI in LM4.0 reflects the new parameterization of light limitation on the maximum attainable LAI. In this parameterization, if the light level at the bottom of the canopy is so low that the leaves cannot support their own physiological demands, the lifetime of these leaves is reduced.

In addition to the differences in LAI values, the two models also differ in the cold evergreentemperate deciduous forest boundary (depicted as sharp LAI gradients around $40-60^{\circ} \mathrm{N}$ in Fig.1a vs. Fig.1b). The cold evergreen tree type is assigned when the number of cold months (average canopy air temperature below $10^{\circ} \mathrm{C}$ ) is in the range 9-12 for LM3.0, but 7-9 for LM4.0. The change was made to better locate the region of cold evergreen forest, as reflected in MODIS reflectance observations (Milly et al., 2014). The change in the cold evergreen temperate deciduous forest boundary from LM3.0 to LM4.0 affects the simulated seasonality of $\mathrm{V}_{\mathrm{d}, \mathrm{O} 3}$ in these areas, as illustrated in Figure $\mathbf{2}$ for three northern European forest sites. LAI is a primary driver of the observed seasonality in $\mathrm{V}_{\mathrm{d}, \mathrm{O} 3}$ at a moorland site in Auchencorth Moss, Scotland and a mixed coniferous forest at Ulborg, Denmark (Fowler et al., 2001; Mikkelsen et al., 2004). At the far northern Hyytiala coniferous forest site, the dormancy of vegetation, below-zero temperatures, and snow cover result in low and relatively stable observed $\mathrm{V}_{\mathrm{d}, \mathrm{O} 3}$ in winter (Rannik et al., 2012). These sites are located in temperate deciduous forest areas in LM3.0, thus both the interannual spread and magnitude of wintertime $\mathrm{V}_{\mathrm{d}, \mathrm{O} 3}$ are underestimated, due to a lack of wintertime LAI. In contrast, LM4.0 better captures the observed seasonality of $\mathrm{V}_{\mathrm{d}, \mathrm{O} 3}$ at these sites (though some biases remain, e.g., too large 
springtime $\mathrm{V}_{\mathrm{d}, \mathrm{O} 3}$ at Hyytiala). For the growing season, both models simulate lower $\mathrm{V}_{\mathrm{d}, \mathrm{O} 3}$ than observed at Ulborg. This discrepancy may reflect uncertainties in $\mathrm{V}_{\mathrm{d}, \mathrm{O} 3}$ measurements derived from the gradient method, which in general are greater than those obtained with the eddy correlation method (Wu et al., 2015).

\subsection{Critical leaf temperature}

Figure 3 illustrates the influence of changes in critical leaf temperature $\left(T_{c}\right)$ on seasonality of simulated $\mathrm{V}_{\mathrm{d}, \mathrm{O} 3}$ at a temperate deciduous forest. Cold-triggering of leaf drop in LM3.0 occurs at $5^{\circ} \mathrm{C}$ for $\mathrm{C} 3$ grass and $10^{\circ} \mathrm{C}$ for other vegetation types (Shevliakova et al., 2009). In the standard version of $\mathrm{LM} 4.0, \mathrm{~T}_{\mathrm{c}}$ is set to $0^{\circ} \mathrm{C}$ for all vegetation types, but we find that the model overestimates observed LAI and $\mathrm{V}_{\mathrm{d}, \mathrm{O} 3}$ in spring at Harvard Forest. Thus, we conduct a suite of LM4.0 sensitivity simulations with $\mathrm{T}_{\mathrm{c}}$ for deciduous trees set to $0^{\circ} \mathrm{C}, 5^{\circ} \mathrm{C}$, and $10^{\circ} \mathrm{C}$, respectively, and examine the modeled seasonal green-up in midlatitude regions as compared to MODIS NDVI observations. With $\mathrm{T}_{\mathrm{c}}$ set to $10^{\circ} \mathrm{C}$, the modeled NDVI at Harvard Forest in March agrees well with MODIS data, consistent with the better agreement in $\mathrm{V}_{\mathrm{d}, \mathrm{O} 3}$ at the site compared with the $\mathrm{T}_{\mathrm{c}}=0^{\circ} \mathrm{C}$ simulation, but the green-up in the central eastern U.S. occurs too late. With $\mathrm{T}_{\mathrm{c}}=0^{\circ} \mathrm{C}$ the modeled NDVI above $40^{\circ} \mathrm{N}$ is too high in December, indicating that deciduous trees in that area do not drop leaves realistically. Overall, the simulation with

$\mathrm{T}_{\mathrm{c}}$ set to $5^{\circ} \mathrm{C}$ best matches the seasonal cycle of green leaf area inferred from satellite data over North America and other midlatitude regions, although it still overestimates $\mathrm{V}_{\mathrm{d}, \mathrm{O} 3}$ in May observed at Harvard Forest. Based on our evaluation, we adopt $\mathrm{T}_{\mathrm{c}}=5^{\circ} \mathrm{C}$ for deciduous trees and $\mathrm{C} 4$ grass in the LM4.0 simulations with interactive dry deposition. $\mathrm{T}_{\mathrm{c}}$ for the other vegetation types are set to $0^{\circ} \mathrm{C}$ as in LM3.1 (Milly et al., 2014). Changes in $\mathrm{T}_{\mathrm{c}}$ modulate the growth cycle of vegetation and thus can also influence simulated LAI values and interannual variability of $\mathrm{V}_{\mathrm{d}, \mathrm{O} 3}$ in summer.

\subsection{Water availability}

We next examine the influence of spatial and seasonal variations of water availability on stomatal conductance and $\mathrm{V}_{\mathrm{d}, \mathrm{O} 3}$, by contrasting sites in Southern Europe with a Mediterranean climate and those in Northern Europe with a wet summer. Located on the western coasts of Europe (roughly between $35^{\circ}$ to $45^{\circ} \mathrm{N}$ ), a Mediterranean climate is characterized by rainy winters and springs but dry summers (Figure 4). In May, with plentiful precipitation throughout Europe, LM4.0 simulates a daytime mean $(9 \mathrm{am}-3 \mathrm{pm}) \mathrm{O}_{3}$ stomatal deposition rate $\left(\mathrm{G}_{\mathrm{s}, \mathrm{O} 3}\right)$ of 0.4 to $0.6 \mathrm{~cm} \mathrm{~s}^{-1}$. The $\mathrm{G}_{\mathrm{s}, \mathrm{O} 3}$ values decrease to below $0.2 \mathrm{~cm}$ $\mathrm{s}^{-1}$ in Mediterranean Europe during August with dry conditions. The modelled spring to summer $\mathrm{G}_{\mathrm{s}, \mathrm{O} 3}$ decreases are consistent with measurements from a typical Mediterranean maquis ecosystem in Italy during May versus July of 2007 (Gerosa et al., 2009a; Rydsaa et al., 2016). Simultaneous measurements of water vapor and $\mathrm{O}_{3}$ fluxes at an evergreen Holm Oak forest at Castelporziano, Italy, indicate that stomatal pathways explained almost the totality of $\mathrm{O}_{3}$ fluxes during winter, but less than $50 \%$ in daytime during summer under condition of drought stress (Fares et al., 2014).

Figures 5a and 5b compare monthly daytime mean $\mathrm{V}_{\mathrm{d}, \mathrm{O} 3}$ at Castelporziano from observations and GFDL land model simulations. Both LM3.0 and LM4.0 capture the observed decreases in $\mathrm{V}_{\mathrm{d}, \mathrm{O} 3}$ from April to August at the Mediterranean Oak Forest, driven by the reduced efficiency of stomatal deposition under drought stress, with LM4.0 simulating higher $\mathrm{V}_{\mathrm{d}, \mathrm{O} 3}$ in April-May. Water availability also influences the spatial variability of $\mathrm{V}_{\mathrm{d}, \mathrm{O} 3}$ in Northern versus Southern Europe during late summer. For example, Figures 5c and 5d 
compare July-August mean diurnal cycle of $\mathrm{V}_{\mathrm{d}, \mathrm{O} 3}$ at Castelporziano versus over a holm oak forest at Alice Holt, England (Fowler et al., 2009). Observed July-August daytime mean $\mathrm{V}_{\mathrm{d}, \mathrm{O} 3}$ is $0.6-1.2 \mathrm{~cm} \mathrm{~s}^{-1}$ at Alice Holt, but decreases to $0.2-0.3 \mathrm{~cm} \mathrm{~s}^{-1}$ at Castelporziano. LM4.0 generally reproduces the observed $\mathrm{V}_{\mathrm{d}, \mathrm{O} 3}$ variability between the two sites and attributes it to large-scale decreases in stomatal conductance associated with water stress in the Southern European forest during late summer (Fig.4). Note that changes in LAI are not the major driver of the modeled $\mathrm{V}_{\mathrm{d}, \mathrm{O} 3}$ variability between the sites. Large vapor pressure deficits, especially in the Mediterranean region, may also lead to limitation of stomatal conductance. Such an effect has been previously observed for water-saving tree species such as Holm Oak (Quercus ilex), which tend to close their stomata to prevent severe water losses (Manes et al., 2007; Mereu et al., 2009). This phenomenon is often associated with drought conditions; it is therefore not easy to disentangle single effects.

For croplands over Europe (Fig.6a), LM4.0 simulates higher late-summer $\mathrm{V}_{\mathrm{d}, \mathrm{O} 3}$ values in the north, consistent with the spatial patterns of precipitation and stomatal conductance (Fig.4). Interestingly, the simulated north-to-south gradient in daytime mean $\mathrm{V}_{\mathrm{d}, \mathrm{O} 3}$ to croplands mimics the $\mathrm{V}_{\mathrm{d}, \mathrm{O} 3}$ variations inferred from $\mathrm{O}_{3}$ eddy covariance measurements at a potato field in Scotland (Coyle et al., 2009) and three maize crop sites in France (Stella et al., 2011) (color filled circles in Fig.6a). Sampling LM4.0 at Grignon in northern France with plentiful precipitation and at Lamasquere in a dry Mediterranean climate indicates that reduction of stomatal deposition during daytime can explain the changes in total $\mathrm{V}_{\mathrm{d}, \mathrm{O} 3}$ at the two sites (Fig.6b and 6c). For Lamasquere, the observed low LAI (Table 1) likely contributes to lower observed $\mathrm{V}_{\mathrm{d}, \mathrm{O} 3}$, although the modeled LAI does not show much difference at the sites (Fig.S3). During daytime at Grignon, the stomatal pathway represents half of the total deposition in the model, consistent with that inferred from water vapor flux measurements at Grignon when maize was fully developed (Stella et al., 2011). The model slightly underestimates daytime $\mathrm{V}_{\mathrm{d}}$, O3 at the Gilchriston potato field in Scotland $\left(0.7 \mathrm{~cm} \mathrm{~s}^{-1}\right.$ in the model compared to $0.8 \mathrm{~cm} \mathrm{~s}^{-1}$ deduced from observations; Fig.6a). One possible explanation is an underestimate of enhanced non-stomatal deposition to a wet canopy surface, which Coyle et al. (2009) suggested was an important process at the Gilchriston site.

Seasonal water availability is also found to affect stomatal conductance and total $\mathrm{V}_{\mathrm{d}, \mathrm{O} 3}$ in evergreen tropical forests over Amazon and South Asia (Figure 7). Short-term (10-20 days) observations in the Amazon rainforest show that daytime mean $\mathrm{V}_{\mathrm{d}, \mathrm{O} 3}$ decreases from 1.1-1.8 $\mathrm{cm} \mathrm{s}^{-1}$ in the wet season (February-March-April) to only $0.5 \mathrm{~cm} \mathrm{~s}^{-1}$ in the dry season (JuneJuly-August) (filled circles in Fig.7a) (Fan et al., 1990; Rummel et al., 2007). LM4.0 captures the observed anomalies, with simulated $\mathrm{V}_{\mathrm{d}, \mathrm{O} 3}$ in the southeast parts of the Amazon rainforest decreasing from $0.7-0.8 \mathrm{~cm} \mathrm{~s}^{-1}$ in the wet season to $0.2-0.3 \mathrm{~cm} \mathrm{~s}^{-1}$ in the dry season (Fig.7a). Mean $\mathrm{V}_{\mathrm{d}, \mathrm{O} 3}$ magnitude over Amazon in the model is generally smaller than observations. While the source of this problem is unclear, it may reflect some combined influence from differences in the scales of observations and model simulations, errors in the atmospheric forcings, the uncertainty in the model's parameters and structure, and the uncertainty in the flux measurements themselves. Over South Asia, observed daytime mean $\mathrm{V}_{\mathrm{d}, \mathrm{O} 3}$ above a tropical forest in Thailand is $0.6 \mathrm{~cm} \mathrm{~s}^{-1}$ in the wet season (June-July-August) compared to $0.3 \mathrm{~cm} \mathrm{~s}^{-1}$ in the dry (February-March-April) season (Matsuda et al., 2005; Matsuda et al., 2006), consistent with LM4.0 simulations (Fig.7b). The seasonality of $\mathrm{V}_{\mathrm{d}, \mathrm{O} 3}$ in these tropical forests is primarily driven by the seasonality of regional precipitation that affects stomatal conductance through changes in soil moisture (Fig.S4). The seasonal changes in LAI are small for most areas (Fig.S5). The model indicates that $\mathrm{O}_{3}$ uptake by tropical forest in India is also susceptible to drought effects in the dry season. Over the 
rainforest in Malaysia and Indonesia, for comparison, the lack of seasonality in rainfall leads to year-round active $\mathrm{O}_{3}$ uptake, with simulated daytime mean $\mathrm{V}_{\mathrm{d}, \mathrm{O} 3}$ ranging from $0.7-0.9 \mathrm{~cm}$ $\mathrm{s}^{-1}$ (Fig.7b), close to the observed value of $0.9 \mathrm{~cm} \mathrm{~s}^{-1}$ from a rainforest in Borneo during July 2008 (filled circles in Fig.7b, data from Fowler et al., 2011).

\section{Interannual variability of ozone deposition velocity 4.1 Observed reduction of ozone deposition to forest under drought}

Ozone concentrations and fluxes have been measured continuously during 1995-2000 by a gradient method at a Norway spruce-dominated forest at Ulborg, Denmark (Mikkelsen et al., 2004). The data are analyzed here to examine interannual variability of $\mathrm{V}_{\mathrm{d}, \mathrm{O} 3}$ and its relationship to large-scale drought in Northern Europe. We calculate five years of half-hourly $\mathrm{V}_{\mathrm{d}, \mathrm{O} 3}$ from $\mathrm{O}_{3}$ concentrations and flux measurements at $18-36 \mathrm{~m}$ above the ground. We remove outliers by rejecting any half-hourly $\mathrm{V}_{\mathrm{d}, \mathrm{O} 3}$ values falling outside \pm 5 standard deviations of the half-hourly time series during May-September. Figure 8a shows the time series of the monthly daytime mean (9am-3pm) $\mathrm{V}_{\mathrm{d}, \mathrm{O} 3}$ from 1995 to 2000, with drought events indicated. Drought events are defined using the Standardized PrecipitationEvapotranspiration Index (SPEI) (Begueria et al., 2014), calculated using monthly precipitation and potential evapotranspiration from the Climate Research Unit dataset (Harris et al., 2014). SPEI can be calculated over a variable integration time scale (e.g., SPEI06, 6month SPEI, integrates water status over the previous 6 months), with more negative values indicating more severe drought relative to long-term average conditions. We use SPEI06 $<-1$ as the threshold for a drought event to calculate the percentage area in drought over a specific region: for instance, Northern Europe $\left(50^{\circ} \mathrm{N}-65^{\circ} \mathrm{N}, 10^{\circ} \mathrm{W}-30^{\circ} \mathrm{E}\right)$, for the purpose of investigating large-scale climate conditions influencing $\mathrm{V}_{\mathrm{d}, \mathrm{O} 3}$ variability at Ulborg. Monthly daytime mean $\mathrm{V}_{\mathrm{d}, \mathrm{O} 3}$ at Ulborg are lowest in 1995-1996 during a severe, prolonged drought in Denmark (Fig.8b). In contrast, observed daytime mean $\mathrm{V}_{\mathrm{d}, \mathrm{O} 3}$ are highest in 1998 when persistent rainfall across Northern Europe maintained sufficient soil moisture (Fig.8c). Using a bootstrap technique, we find that the highest and lowest daytime mean $\mathrm{V}_{\mathrm{d}, \mathrm{O} 3}$ values in each month are significantly different between 1996 and 1998 at a 95\% confidence level.

Figure 9 further demonstrates reduced $\mathrm{V}_{\mathrm{d}, \mathrm{O} 3}$ to North American deciduous forests under conditions of large-scale drought stress. Dry deposition of $\mathrm{O}_{3}$ is derived from gradient measurements at Borden Forest in southern Ontario, Canada from May 2008 to April 2013 (Wu et al., 2016). The five-year measurements at Borden Forest include the 2012 North American drought, with its peak occurred during a record-breaking heat wave in late June to July. The drought covered most of the U.S. and Eastern Canada, including southern Ontario. Our analysis shows that daytime mean $\mathrm{V}_{\mathrm{d}, \mathrm{O} 3}$ at Borden Forest decreases by $\sim 0.40 \mathrm{~cm} \mathrm{~s}^{-1}$ in observations and $\sim 0.45 \mathrm{~cm} \mathrm{~s}^{-1}$ in the model during the dry and hot July of 2012 relative to the wet and cool July of 2009 (Fig.9a-d). Supporting the conclusion drawn from sparse gradient measurements, LM4.0 indicates that the drought-induced $\mathrm{V}_{\mathrm{d}, \mathrm{O} 3}$ decreases in 2012 were widespread across eastern North America (Fig.9e,f). The model shows little change $(<1)$ in LAI between the two summers (Fig.S6). The limitation of stomatal conductance associated with soil drying is the primary driver of simulated $\mathrm{V}_{\mathrm{d}, \mathrm{O} 3}$ decreases during such large-scale mid-latitude droughts. The reduced $\mathrm{O}_{3}$ uptake by vegetation exacerbated the buildup of surface $\mathrm{O}_{3}$ levels to $75-135$ ppbv (8-hour average) at monitoring stations across the central and eastern U.S. during the 2012 heat wave and drought. 


\subsection{Influence of model precipitation biases}

We next examine the influence of uncertainties in model precipitation on $\mathrm{V}_{\mathrm{d}, \mathrm{O} 3}$ means and extremes, recognizing that precipitation is the main driver of variability in drought and stomatal conductance. Using Europe as an example, we contrast regional $\mathrm{V}_{\mathrm{d}, \mathrm{O} 3}$ variability simulated in LM3.0 driven by the observation-based meteorological forcings (including precipitation) versus LM3.0 coupled with the GFDL Atmospheric Model Version 3 (hereafter "AM3_LM3"). AM3_LM3 is nudged to NCEP horizontal winds using a pressure-dependent nudging technique (Lin et al., 2012; Lin et al., 2015), while precipitation is simulated internally by the model. Fig.8d shows that standalone LM3.0 simulates $\mathrm{V}_{\mathrm{d}, \mathrm{O} 3}$ decreases in Northern Europe and increases in Southern Europe in July-August 1996 relative to 1998, consistent with the dry versus wet forested areas inferred from SPEI. Standalone LM3.0 simulates $\mathrm{V}_{\mathrm{d}, \mathrm{O} 3}$ anomalies at Ulborg $\left(\sim 0.4 \mathrm{~cm} \mathrm{~s}^{-1}\right)$ that are comparable to the observed values. In contrast, $\mathrm{V}_{\mathrm{d}, \mathrm{O} 3}$ anomalies at Ulborg in the coupled model AM3_LM3 are weaker by a factor of two than observed, with no systematic changes in $\mathrm{V}_{\mathrm{d}, \mathrm{O} 3}$ over Southern Europe (Fig.8e). These biases are caused by limitations in the accurate simulation of regional rainfall and drought, particularly their extremes, by the model when constrained only by observed horizontal winds and sea surface temperatures.

AM3 underestimates precipitation in Southern Europe (Fig.10a-b). Given its coarse resolution $\left(\sim 200 \times 200 \mathrm{~km}^{2}\right)$, the model fails to reproduce intense precipitation in the European Alps. These precipitation biases not only affect the mean of $\mathrm{V}_{\mathrm{d}, \mathrm{O} 3}$ but also extremes, as shown in the time series analysis of JJA daytime mean $\mathrm{V}_{\mathrm{d}, \mathrm{O} 3}$ to natural forests averaged over Southern Europe from 1960 to 2014 (Fig.10c). In standalone LM3.0 driven by observed atmospheric forcings, summertime $\mathrm{V}_{\mathrm{d}, \mathrm{O} 3}$ over Southern Europe varies strongly on interannual to decadal time scales, correlating with the drought index. Particularly, LM3.0 simulates the lowest $\mathrm{V}_{\mathrm{d}, \mathrm{O} 3}$ over the 55-year record during the 2003 European mega-drought. In the coupled model AM3_LM3, the interannual variability of $\mathrm{V}_{\mathrm{d}, \mathrm{O} 3}$ is weaker by approximately a factor of two and the $\mathrm{V}_{\mathrm{d}, \mathrm{O} 3}$ decrease in summer 2003 is not the most extreme over the past halfcentury. While we only have the long-term coupled model simulation available from AM3_LM3 with interactive dry deposition, examination of precipitation fields from AM4 with higher horizontal resolution (Zhao et al., 2018a,b), still shows a similar difficulty in simulating the regional drought extremes like summer 2003. Thus, the coupled AM4_LM4 model is expected to simulate weaker $\mathrm{V}_{\mathrm{d}, \mathrm{O} 3}$ variability than standalone LM4.0.

\section{Global distributions of $\mathrm{V}_{\mathrm{d}, \mathrm{O} 3}$ and contributions from stomatal pathways}

Daytime mean $\mathrm{V}_{\mathrm{d}, \mathrm{O} 3}$ during the warm season in LM4.0 typically ranges from 0.6 to $1.0 \mathrm{~cm} \mathrm{~s}^{-1}$ for natural and secondary vegetation (primarily forests), 0.4 to $0.7 \mathrm{~cm} \mathrm{~s}^{-1}$ for croplands, and 0.3 to $0.5 \mathrm{~cm} \mathrm{~s}^{-1}$ for pastures in the absence of drought (Fig.S7). These values are generally consistent with observations (Table 1). We focus next on a detailed evaluation of JJA daytime mean $\mathrm{V}_{\mathrm{d}, \mathrm{O} 3}$ to European and North American forests, where observations are relatively dense. Drought stress and reduced stomatal uptake during late summer in the Mediterranean region (Section 3.3) lead to a north-to-south contrast in observed $\mathrm{V}_{\mathrm{d}, \mathrm{O} 3}$, with higher $\mathrm{V}_{\mathrm{d}, \mathrm{O} 3}$ in Northern Europe than in Southern Europe (Fig.11a). Over North America, $\mathrm{V}_{\mathrm{d}, \mathrm{O} 3}$ generally increases from west to east (Fig.11b), driven by increases in LAI (Fig.1). The observed regional variability of $\mathrm{V}_{\mathrm{d}, \mathrm{O} 3}$ over Europe and North America is well simulated in LM4.0. The largest discrepancy between observations and simulations occurs at Blodgett Forest in California (small triangle in Fig.11b), where observed JJA daytime $\mathrm{V}_{\mathrm{d}, \mathrm{O} 3}$ is $0.92 \mathrm{~cm}$ $\mathrm{s}^{-1}$ for 2001-2007 (Fares et al., 2010) and $0.5 \mathrm{~cm} \mathrm{~s}^{-1}$ for 1999 (Kurpius et al., 2002), versus 
$0.4 \mathrm{~cm} \mathrm{~s}^{-1}$ in the model. Fares et al. (2010) suggested that in-canopy chemical reactions with terpenoids emitted by the ponderosa pine ecosystem at Blodgett Forest are mainly responsible for the rapid $\mathrm{O}_{3}$ sink in their observations, whereas the deposition scheme in our model does not include the influence of in-canopy chemistry.

Figures 12a-b depict the 1990-2014 mean contribution of stomatal pathways to the total $\mathrm{V}_{\mathrm{d}, \mathrm{O} 3}$ in LM4.0 for Northern Hemisphere summer (see also Figs. S8-S9 for the global maps). Considering both nighttime and daytime conditions, stomatal pathways account for $\sim 50 \%$ of the total $\mathrm{V}_{\mathrm{d}, \mathrm{O} 3}$ to natural or secondary vegetation and $\sim 25 \%$ to croplands or pastures at northern mid-latitude regions without drought disturbances. However, considering only daytime conditions, especially under optimal climatic conditions (e.g., plentiful precipitation) for plant functioning, stomatal pathways represent up to $75 \%$ of the total $\mathrm{V}_{\mathrm{d}, \mathrm{O} 3}$ for natural or secondary vegetation, $40 \%$ for croplands, and 35\% for pastures. In the dry Mediterranean climate, the daytime contributions of stomatal deposition decrease by almost a factor of two compared to the other regions that do not typically experience late summer droughts (Fig.12a). These model estimates of $\mathrm{V}_{\mathrm{d}, \mathrm{O} 3}$ stomatal fraction are close to the sparse observation-based estimates from scaling eddy covariance measurements of water vapor or $\mathrm{CO}_{2}$ fluxes. The summer daytime $(9 \mathrm{am}-3 \mathrm{pm})$ stomatal fraction estimated from observations is $41-82 \%$ (multiyear mean is 59\%) at Harvard Forest for 1990-2000 (Clifton et al., 2017) and 65\% at Kane Experiment Site for 1997 in the eastern U.S. (Zhang et al., 2006). Over Europe, estimates are 65-80\% at an oak forest in England for 2005 (Coyle et al., 2006), 60\% at a boreal pine forest in Finland for 2001-2010 (Rannik et al., 2012), and $<50 \%$ at a Mediterranean oak forest in Italy for 2003-2014 and 2012-2013 (Gerosa et al., 2009b; Fares et al., 2014). Note that the observation-derived stomatal $\mathrm{O}_{3}$ fluxes suffer from uncertainties due to the inversion of Penman-Monteith equation used to calculate stomatal conductance from evapotranspiration, particularly at sites where the evaporative component of water fluxes is not negligible (Fares et al., 2018).

Figures 12c-d illustrate the interannual variability in $\mathrm{JJA}$ daytime mean $\mathrm{V}_{\mathrm{d}, \mathrm{O} 3}$ for natural forests in LM4.0, expressed as the relative standard deviation (ratio of the standard deviation to the mean) and the ratio of maximum to minimum values across 35 years from 1980 to 2014. The model indicates that semi-arid areas of western Europe, eastern North America, and northeastern China have the largest interannual variability in $\mathrm{V}_{\mathrm{d}, \mathrm{O} 3}$, with the relative standard deviation ranging from 15 to $35 \%$. Over these regions, summertime mean $\mathrm{V}_{\mathrm{d}, \mathrm{O} 3}$ for the highest year can be a factor of 2 to 4 higher than that for the lowest, with significant implications for surface $\mathrm{O}_{3}$ interannual variability.

\section{Influence of changes in ozone deposition on surface ozone}

We discuss in this section the influence on simulated surface $\mathrm{O}_{3}$ from changes in tracer dry deposition velocities. We conduct two 10-year AM4 simulations (2005-2014) at 100x100 $\mathrm{km}^{2}$ horizontal resolution, each using AM3-like full chemistry, winds nudged to NCEP reanalysis (Lin et al., 2012; Lin et al., 2015; Lin et al., 2017), and the same anthropogenic emissions (Hoesly et al., 2018), but with different dry deposition velocities, one using the default AM4 dry deposition velocities obtained from the Wesely scheme implemented in the GEOS-Chem model (Silva \& Heald, 2018), the other using deposition velocities calculated from GFDL LM4.0 driven by observed atmospheric forcings (AM4_LM4dd). We focus our evaluation on the seasonal mean of the maximum daily 8-hour average (MDA8) $\mathrm{O}_{3}$ over 2005-2014, a period when monitoring sites were densely clustered across mid-latitude North America and Europe. TOAR data are relatively sparse over East Asia. Thus, we additionally 
draw upon surface $\mathrm{O}_{3}$ observations available during 2013-2017 from China's Ministry of Environmental Protection (CNMEP).

Spring and summertime mean surface MDA8 $\mathrm{O}_{3}$ as observed and simulated by the two AM4 simulations, along with comparisons of $\mathrm{V}_{\mathrm{d}, \mathrm{O} 3}$, are shown in Figs.13-14 for western Europe, Figs.15-16 for North America, and Figs.17-18 for East Asia. Using $V_{\mathrm{d}, \mathrm{O} 3}$ from LM4.0 leads to a reduction of springtime mean $\mathrm{MDA} 8 \mathrm{O}_{3}$ biases by $\sim 10 \mathrm{ppbv}$ and of root-mean-square deviation (rmsd) by $\sim 8$ ppbv throughout Northern Hemisphere in AM4 compared to using $\mathrm{V}_{\mathrm{d}, \mathrm{O} 3}$ from the Wesely scheme in GEOS-Chem. For summer, the improvement is most prominent at northern high-latitudes (above $45^{\circ} \mathrm{N}$ ) where coniferous trees dominate in LM4.0. Some of these improvements reflect changes in the non-stomatal deposition parameterizations in LM4.0, including a more realistic treatment of ground resistance over non-vegetated surfaces (affecting $\mathrm{V}_{\mathrm{d}, \mathrm{O} 3}$ over North Africa, western U.S., and western China) and cuticular resistance over coniferous forests (Paulot et al., 2018). The height of the bottom atmospheric layer (centered at 35m in LM4/AM4 and 60m in GEOS-Chem) may influence mean $\mathrm{V}_{\mathrm{d}, \mathrm{O} 3}$ levels simulated in the models. Nevertheless, $\mathrm{V}_{\mathrm{d}, \mathrm{O} 3}$ from LM4.0 agrees well with observations, while GEOS-Chem underestimates observed JJA mean $\mathrm{V}_{\mathrm{d}, \mathrm{O} 3}$ at northern European coniferous forest sites by a factor of two (comparing Fig.14 with observations in Fig.2). Furthermore, the spatial and seasonal variability of stomatal deposition in LM4.0 is dynamic, depending not only on LAI but also on climate conditions via their effects on plant functioning. In contrast, $\mathrm{V}_{\mathrm{d}, \mathrm{O} 3}$ from the Wesely scheme in GEOS-Chem generally increases from spring to summer, simply scaling with the seasonal changes in LAI (Silva \& Heald, 2018), not accounting for variations during the wet versus dry season that are inferred from observations (Section 3.3) and from LM4.0 simulations for Mediterranean Europe, the U.S. Pacific Northwest, Mexico, and South Asia (Figs.14, 16, and 18). Silva and Heald (2018) showed that the Wesely scheme in GEOS-Chem generally reproduces the seasonal mean observed $\mathrm{V}_{\mathrm{d}, \mathrm{O} 3}$ averaged across sites globally but has limited skill $\left(\mathrm{R}^{2}=0.04\right)$ in simulating the site-to-site variations in observations, supporting that the Wesely scheme has a lack of sensitivity to local environmental variables.

We note that summertime surface $\mathrm{O}_{3}$ in the AM4_LM4dd simulations are still biased high over populated regions of the eastern U.S., western Europe and eastern China, as in many other global models (Young et al., 2018). Since LM4.0 does not have systematic biases in $\mathrm{V}_{\mathrm{d}, \mathrm{O} 3}$ over these regions during the growing season, we suggest that these surface $\mathrm{O}_{3}$ biases may reflect some other uncertainties, such as in isoprene chemistry, chemical $\mathrm{O}_{3}$ loss, regional $\mathrm{O}_{3}$ precursor emissions, and difficulty in resolving $\mathrm{O}_{3}$ vertical gradients (Fiore et al., 2014; Travis et al., 2016; Lin et al., 2017).

\section{Conclusions and Recommendations}

Using observations and model simulations of dynamic vegetation and atmospheric chemistry over the past half-century (1960-2014), we explore the role of ecosystem-atmosphere interactions on $\mathrm{O}_{3}$ dry deposition and air quality. Our observational analysis supports a key role for water availability in modulating $\mathrm{O}_{3}$ deposition variability on seasonal to interannual time scales via changes in stomatal conductance, with the effects on monthly mean daytime $\mathrm{V}_{\mathrm{d}, \mathrm{O} 3}$ variability as large as a factor of two.

We evaluate an interactive $\mathrm{O}_{3}$ dry deposition scheme within the GFDL LM3.0 and LM4.0 dynamic vegetation land models driven by observed atmospheric forcings. An improved 
simulation of several important properties of vegetation in LM4.0 relative to LM3.0, including the geographical distribution of vegetation types and LAI, reduces biases in the simulation of $\mathrm{V}_{\mathrm{d}, \mathrm{O} 3}$ seasonality at some observational sites (Figs. 1-3). Compared to the widely-used Wesely scheme, the most novel feature of the GFDL dry deposition scheme is the photosynthesis-based parameterization of $\mathrm{O}_{3}$ stomatal deposition as a function of phenology, soil moisture, vapor pressure deficit, and $\mathrm{CO}_{2}$ concentration. These new features allow the models to represent successfully the observed $\mathrm{V}_{\mathrm{d}, \mathrm{O} 3}$ variability during the dry versus wet season over evergreen forests in Mediterranean Europe, South Asia, and the Amazon (Figs. 4-7). On interannual time scales, large-scale drought can reduce $\mathrm{V}_{\mathrm{d}, \mathrm{O} 3}$ by $\sim 50 \%$, as we demonstrated with observations at a coniferous forest in Europe and at a deciduous forest in North America, consistent with the standalone LM3.0/LM4.0 simulations (Figs.8 and 9). Our modeling analysis, as supported by multiple observational datasets, suggests that limitation in stomatal conductance due to soil moisture deficits (as opposed to LAI changes) is the primary driver of $\mathrm{V}_{\mathrm{d}, \mathrm{O} 3}$ variability during large-scale drought events. On basis of data over one forest site, Clifton et al. (2019) notice enhanced non-stomatal $\mathrm{O}_{3}$ deposition in dry years associated with greater soil uptake. This effect is not parameterized in our model and its significance for driving $\mathrm{V}_{\mathrm{d}, \mathrm{O} 3}$ variability during sub-continental to continental scale drought events (e.g., in summer 2003 across Europe) requires further investigation.

Climate change may reduce the reliability of water supplies that are important for both society and ecosystems. The modeling system presented in this study offers new research opportunities to study how climate change and water availability influence air quality via changes in pollutant deposition sinks to vegetation, a process that is often overlooked in current air quality projections. Changes in $\mathrm{O}_{3}$ deposition associated with seasonal hydroclimate variability may modulate surface $\mathrm{O}_{3}$ seasonality, such as worsening the buildup of surface $\mathrm{O}_{3}$ pollution during the dry season. On interannual time scales, the model suggests that, over northern mid-latitude forested regions, monthly mean $\mathrm{V}_{\mathrm{d}, \mathrm{O} 3}$ for the highest year is two to four times that of the lowest, with significant implications for surface $\mathrm{O}_{3}$ variability (Fig.12). Specifically, we show that summertime $\mathrm{V}_{\mathrm{d}, \mathrm{O} 3}$ over European forests varies strongly on interannual to multi-decadal time scales over the period 1960-2014, correlating with an index of drought (Fig.10). A forthcoming manuscript will explore how these changes influence the observed historical surface $\mathrm{O}_{3}$ trends and pollution extremes. Feedbacks from ecosystem-atmosphere interactions and associated changes in $\mathrm{O}_{3}$ deposition will impact the severity of extreme surface $\mathrm{O}_{3}$ pollution episodes in present and future climates.

There are several limitations in the current version of our dry deposition models, such as neglect of in-canopy chemistry, inclusion of which may scavenge $\mathrm{O}_{3}$ and reduce simulated biases with respect to observations, and neglect of possible detrimental impacts on vegetation from exposure to $\mathrm{O}_{3}$ (e.g., Sadiq et al., 2017; Zhou et al., 2018), which may be responsible for a decrease in carbon assimilation up to $20 \%$ (Lombardozzi et al., 2012; Lombardozzi et al., 2015). Given the complexity of various, sometimes offsetting, factors influencing $\mathrm{O}_{3}$ deposition, future work should further explore the importance of stomatal versus nonstomatal processes in driving $\mathrm{V}_{\mathrm{d}, \mathrm{O} 3}$ variability. It is also important to recognize that the land model forcing dataset, particularly precipitation, can have a substantial influence on simulated $\mathrm{O}_{3}$ deposition. We show that the GFDL land model coupled to an atmospheric model, which has low-precipitation biases over Europe, simulates a factor of two weaker interannual variability in $\mathrm{V}_{\mathrm{d}, \mathrm{O} 3}$ than the simulations driven by observed atmospheric forcings (Fig.10). Generally, current climate models have difficulty in accurately simulating hydroclimate variability, particularly the spatial extent, duration, and intensity of regional drought extremes (Shepherd, 2014; Nasrollahi et al., 2015; Ukkola et al., 2018). Thus, 
accurate assessment of ecosystem-atmosphere interactions and future climate impacts on $\mathrm{O}_{3}$ air quality will benefit from improved representation of hydroclimate means and extreme events in coupled atmosphere-ocean-land models.

Advancing knowledge on air quality and ecosystem-atmosphere interactions will benefit from long-term measurements of $\mathrm{O}_{3}$ fluxes, in parallel with carbon fluxes and all supporting measurements. Our model indicates that interannual variability in summertime $\mathrm{V}_{\mathrm{d}, \mathrm{O} 3}$ to forests, driven primarily by the stomatal pathways, is largest (15-35\%) in semi-arid regions of western Europe, eastern North America, and northeastern China (Fig.12). Knowledge of the level of regional $\mathrm{V}_{\mathrm{d}, \mathrm{O} 3}$ variability may be used to guide deployment of key measurement sites intended to track long-term trends in the exchanges of $\mathrm{O}_{3}$, carbon, and water between terrestrial ecosystems and the atmosphere in response to environmental stresses. New opportunities arise in implementing existing ecological monitoring networks, such as FLUXNET (http://fluxnet.fluxdata.org) and ICOS (Integrated Carbon Observation System, https://www.icos-ri.eu/icosresearch-infrastructure) currently investigating $\mathrm{CO}_{2}$ fluxes and plant ecophysiology (Fares et al., 2018). Adding $\mathrm{O}_{3}$ sensors to key agricultural and forest sites in the established networks would represent a win-win strategy.

\section{Acknowledgements:}

This report was prepared by Meiyun Lin under award NA14OAR4320106 from the National Oceanic and Atmospheric Administration, U.S. Department of Commerce. The statements, findings, conclusions, and recommendations are those of the author(s) and do not necessarily reflect the views of the agency. We thank Alex Zhang (Princeton) for processing CNMEP $\mathrm{O}_{3}$ measurements and Vaishali Naik (GFDL) for processing CMIP6 emissions used in this study. We are grateful to John Dunne and Songmiao Fan (GFDL) for helpful comments on the manuscript.

\section{Data Availability:}

Monthly mean deposition velocities from the LM4.0 simulations used in this study are archived at a public data repository at NOAA GFDL (ftp://data1.gfdl.noaa.gov/users/Meiyun.Lin/GBC2019/GFDL-LM4/).

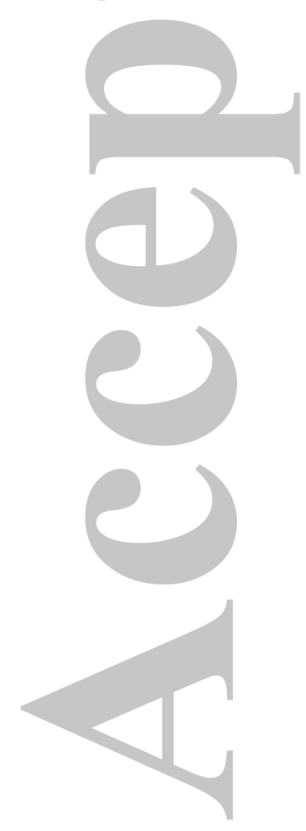




\section{References:}

Andersson, C., \& M. Engardt (2010), European ozone in a future climate: Importance of changes in dry deposition and isoprene emissions, J. Geophys. Res.-Atmos., 115, doi: $10.1029 / 2008 j \mathrm{j} 011690$.

Begueria, S., S. M. Vicente-Serrano, F. Reig, \& B. Latorre (2014), Standardized precipitation evapotranspiration index (SPEI) revisited: parameter fitting, evapotranspiration models, tools, datasets and drought monitoring, Int. J. Clim., 34(10), 3001-3023, doi: 10.1002/joc.3887.

Clifton, O. E., A. M. Fiore, J. W. Munger, S. Malyshev, L. W. Horowitz, E. Shevliakova, et al.(2017), Interannual variability in ozone removal by a temperate deciduous forest, Geophys. Res. Lett., 44(1), 542-552, doi: 10.1002/2016g1070923.

Clifton, O. E., Fiore, A. M., Munger, J.W., \& Wehr, R. (2019). Spatiotemporal controls on observed daytime ozone deposition velocity over northeastern U.S. forests during summer. Journal of Geophysical Research: Atmospheres, 124, 5612-5628. https://doi.org/10.1029/2018JD029073

Coyle, M., Fowler, D., Nemitz, E., Philips, G., Storeton-West, R., Thomas, R., 2006. Field measurements of the ozone flux to vegetation. In: Ozone Umbrella: Effects of Ground-level Ozone on (Upland) Vegetation in the UK. Centre of Ecology and Hydrology, UK, pp. 68104. CEH C02158 Report No. AS 06/02.

Coyle, M., E. Nemitz, R. Storeton-West, D. Fowler, \& J. N. Cape (2009), Measurements of ozone deposition to a potato canopy, Agr Forest Meteorol, 149(3-4), 655-666, doi: 10.1016/j.agrformet.2008.10.020.

Donner, L. J., B. L. Wyman, R. S. Hemler, L. W. Horowitz, Y. Ming, M. Zhao, et al. (2011), The Dynamical Core, Physical Parameterizations, and Basic Simulation Characteristics of the Atmospheric Component AM3 of the GFDL Global Coupled Model CM3, J. Clim., 24(13), 3484-3519, doi: 10.1175/2011jcli3955.1.

Dunne, J. P., J. G. John, A. J. Adcroft, S. M. Griffies, R. W. Hallberg, E. Shevliakova, et al. (2012), GFDL's ESM2 Global Coupled Climate-Carbon Earth System Models. Part I: Physical Formulation and Baseline Simulation Characteristics, J. Clim., 25(19), 6646-6665, doi: $10.1175 / \mathrm{Jcli}-\mathrm{D}-11-00560.1$.

El-Madany, T. S., K. Niklasch, \& O. Klemm (2017), Stomatal and Non-Stomatal Turbulent Deposition Flux of Ozone to a Managed Peatland, Atmosphere-Basel, 8(9), doi: 10.3390/atmos8090175.

Emberson, L. D., N. Kitwiroon, S. Beevers, P. Buker, \& S. Cinderby (2013), Scorched Earth: how will changes in the strength of the vegetation sink to ozone deposition affect human health and ecosystems?, Atmos. Chem. Phys., 13(14), 6741-6755, doi: 10.5194/acp-13-67412013.

Fan, S. M., S. C. Wofsy, P. S. Bakwin, D. J. Jacob, \& D. R. Fitzjarrald (1990), AtmosphereBiosphere Exchange of $\mathrm{Co} 2$ and $\mathrm{O} 3$ in the Central-Amazon-Forest, J. Geophys. Res.-Atmos., 95(D10), 16851-16864, doi: 10.1029/JD095iD10p16851. 
Fares, S., A. Conte, \& A. Chabbi (2018), Ozone flux in plant ecosystems: new opportunities for long-term monitoring networks to deliver ozone-risk assessments, Environ Sci Pollut R, 25(9), 8240-8248, doi: 10.1007/s 11356-017-0352-0.

Fares, S., M. McKay, R. Holzinger, \& A. H. Goldstein (2010), Ozone fluxes in a Pinus ponderosa ecosystem are dominated by non-stomatal processes: Evidence from long-term continuous measurements, Agr Forest Meteorol, 150(3), 420-431, doi:

10.1016/j.agrformet.2010.01.007.

Fares, S., F. Savi, J. Muller, G. Matteucci, \& E. Paoletti (2014), Simultaneous measurements of above and below canopy ozone fluxes help partitioning ozone deposition between its various sinks in a Mediterranean Oak Forest, Agr Forest Meteorol, 198, 181-191, doi: 10.1016/j.agrformet.2014.08.014.

Fares, S., R. Weber, J. H. Park, D. Gentner, J. Karlik, \& A. H. Goldstein (2012), Ozone deposition to an orange orchard: Partitioning between stomatal and non-stomatal sinks, Environ. Pollut., 169, 258-266, doi: 10.1016/j.envpol.2012.01.030.

Finkelstein, P. L., T. G. Ellestad, J. F. Clarke, T. P. Meyers, D. B. Schwede, E. O. Hebert, \& J. A. Neal (2000), Ozone and sulfur dioxide dry deposition to forests: Observations and model evaluation, J. Geophys. Res.-Atmos., 105(D12), 15365-15377, doi: $10.1029 / 2000 j \mathrm{~d} 900185$.

Fiore, A. M., J. T. Oberman, M. Y. Lin, L. Zhang, O. E. Clifton, D. J. Jacob, et al. (2014), Estimating North American background ozone in U.S. surface air with two independent global models: Variability, uncertainties, and recommendations Atmos. Environ., 96, 284300, doi: 10.1016/j.atmosenv.2014.07.045.

Fowler, D., C. Flechard, J. N. Cape, R. L. Storeton-West, \& M. Coyle (2001), Measurements of ozone deposition to vegetation quantifying the flux, the stomatal and non-stomatal components, Water Air Soil Poll, 130(1-4), 63-74, doi: 10.1023/A:1012243317471.

Fowler, D., E. Nemitz, P. Misztal, C. Di Marco, U. Skiba, J. Ryder, et al. (2011), Effects of land use on surface-atmosphere exchanges of trace gases and energy in Borneo: comparing fluxes over oil palm plantations and a rainforest, Philos T R Soc B, 366(1582), 3196-3209, doi: 10.1098/rstb.2011.0055.

Fowler, D., K. Pilegaard, M. A. Sutton, P. Ambus, M. Raivonen, J. Duyzer, et al. (2009), Atmospheric composition change: Ecosystems-Atmosphere interactions, Atmos. Environ., 43(33), 5193-5267, doi: 10.1016/j.atmosenv.2009.07.068.

Ganzeveld, L., C. Ammann, \& B. Loubet (2015), Modelling atmosphere-biosphere exchange of ozone and nitrogen oxides, in Review and Integration of Biosphere-Atmosphere Modelling of Reactive Trace Gases and Volatile Aerosols, edited by R.-S. Massad and B. Loube, pp. pp. 85-105, Springer, Netherlands.

Gardner, W. R. (1960), Dynamic aspects of water availability to plants, Soil Sci., 89, 63-73, doi: 10.1097/00010694-196002000-00001.

Gerosa, G., A. Finco, S. Mereu, R. Marzuoli, \& A. Ballarin-Denti (2009a), Interactions among vegetation and ozone, water and nitrogen fluxes in a coastal Mediterranean maquis ecosystem, Biogeosciences, 6(8), 1783-1798, doi: 10.5194/bg-6-1783-2009. 
Gerosa, G., A. Finco, S. Mereu, M. Vitale, F. Manes, \& A. B. Denti (2009b), Comparison of seasonal variations of ozone exposure and fluxes in a Mediterranean Holm oak forest between the exceptionally dry 2003 and the following year, Environ. Pollut., 157(5), 17371744, doi: 10.1016/j.envpol.2007.11.025.

Hardacre, C., O. Wild, \& L. Emberson (2015), An evaluation of ozone dry deposition in global scale chemistry climate models, Atmos. Chem. Phys., 15(11), 6419-6436, doi: 10.5194/acp-15-6419-2015.

Harris, I., P. D. Jones, T. J. Osborn, \& D. H. Lister (2014), Updated high-resolution grids of monthly climatic observations - the CRU TS3.10 Dataset, Int. J. Clim., 34(3), 623-642, doi: 10.1002/joc.3711.

Helmig, D., L. Ganzeveld, T. Butler, \& S. J. Oltmans (2007), The role of ozone atmospheresnow gas exchange on polar, boundary-layer tropospheric ozone - a review and sensitivity analysis, Atmos. Chem. Phys., 7, doi: 10.5194/acp-7-15-2007.

Helmig, D., P. Boylan, B. Johnson, S. Oltmans, C. Fairall, R. Staebler, et al. (2012), Ozone dynamics and snow-atmosphere exchanges during ozone depletion events at Barrow, Alaska, J. Geophys. Res.-Atmos., 117, doi: 10.1029/2012jd017531.

Hoesly, R. M., S. J. Smith, L. Feng, Z. Klimont, G. Janssens-Maenhout, T. Pitkanen, et al. (2018), Historical (1750-2014) anthropogenic emissions of reactive gases and aerosols from the Community Emissions Data System (CEDS), Geosci. Model Dev., 11, 369-408, doi: 10.5194/gmd-11-369-2018.

Huang, L., E. C. McDonald-Buller, G. McGaughey, Y. Kimura, \& D. T. Allen (2016), The impact of drought on ozone dry deposition over eastern Texas, Atmos. Environ., 127, 176186, doi: 10.1016/j.atmosenv.2015.12.022.

Hurtt, G. C., L. P. Chini, S. Frolking, R. A. Betts, J. Feddema, G. Fischer, et al. (2011), Harmonization of land-use scenarios for the period 1500-2100: 600 years of global gridded annual land-use transitions, wood harvest, and resulting secondary lands, Climatic Change, 109(1-2), 117-161, doi: 10.1007/s10584-011-0153-2.

Iio, A., \& A. Ito (2014), A Global Database of Field-observed Leaf Area Index in Woody Plant Species, 1932-2011. Data set. Available on-line [http://daac.ornl.gov] from Oak Ridge National Laboratory Distributed Active Archive Center, Oak Ridge, Tennessee, USA. , edited.

Jarvis, P. G. (1976), Interpretation of Variations in Leaf Water Potential and Stomatal Conductance Found in Canopies in Field, Philos T Roy Soc B, 273(927), 593-610, doi: 10.1098/rstb.1976.0035.

Kavassalis, S. C., \& J. G. Murphy (2017), Understanding ozone-meteorology correlations: A role for dry deposition, Geophys. Res. Lett., 44(6), 2922-2931, doi: 10.1002/2016g1071791. 
Kukkonen, J., T. Olsson, D. M. Schultz, A. Baklanov, T. Klein, A. I. Miranda, et al. (2012), A review of operational, regional-scale, chemical weather forecasting models in Europe, Atmos. Chem. Phys., 12(1), 1-87, doi: 10.5194/acp-12-1-2012.

Kurpius, M. R., M. McKay, \& A. H. Goldstein (2002), Annual ozone deposition to a Sierra Nevada ponderosa pine plantation, Atmos. Environ., 36(28), 4503-4515, doi: 10.1016/S13522310(02)00423-5.

Lamaud, E., A. Carrara, Y. Brunet, A. Lopez, \& A. Druilhet (2002), Ozone fluxes above and within a pine forest canopy in dry and wet conditions, Atmos. Environ., 36(1), 77-88, doi: 10.1016/S1352-2310(01)00468-X.

Lammertsma, E. I., H. J. de Boer, S. C. Dekker, D. L. Dilcher, A. F. Lotter, \& F. WagnerCremer (2011), Global CO2 rise leads to reduced maximum stomatal conductance in Florida vegetation, Proc. Natl. Acad. Sci. U.S.A., 108(10), 4035-4040, doi:

10.1073/pnas.1100371108.

Leuning, R. (1995), A Critical-Appraisal of a Combined Stomatal-Photosynthesis Model for C-3 Plants, Plant Cell Environ, 18(4), 339-355, doi: 10.1111/j.1365-3040.1995.tb00370.x.

Lin, M., L. W. Horowitz, R. Payton, A. M. Fiore, \& G. Tonnesen (2017), US surface ozone trends and extremes from 1980 to 2014: quantifying the roles of rising Asian emissions, domestic controls, wildfires, and climate, Atmos. Chem. Phys., 17, 2943-2970, doi: 0.5194/acp-17-2943-2017.

Lin, M., A. M. Fiore, L. W. Horowitz, A. O. Langford, S. J. Oltmans, D. Tarasick, \& H. E. Rieder (2015), Climate variability modulates western U.S. ozone air quality in spring via deep stratospheric intrusions, Nat. Commun., 6(7105), doi: 10.1038/ncomms8105.

Lin, M., A. M. Fiore, L. W. Horowitz, O. R. Cooper, V. Naik, J. Holloway, et al. (2012), Transport of Asian ozone pollution into surface air over the western United States in spring, J. Geophys. Res., 117, doi: 10.1029/2011jd016961.

Lombardozzi, D., S. Levis, G. Bonan, \& J. P. Sparks (2012), Predicting photosynthesis and transpiration responses to ozone: decoupling modeled photosynthesis and stomatal conductance, Biogeosciences, 9(8), 3113-3130, doi: 10.5194/bg-9-3113-2012.

Lombardozzi, D., S. Levis, G. Bonan, P. G. Hess, \& J. P. Sparks (2015), The Influence of Chronic Ozone Exposure on Global Carbon and Water Cycles, J. Clim., 28(1), 292-305, doi: 10.1175/Jcli-D-14-00223.1.

Long, S. P., E. A. Ainsworth, A. Rogers, \& D. R. Ort (2004), Rising atmospheric carbon dioxide: Plants face the future, Annu Rev Plant Biol, 55, 591-628, doi: 10.1146/annurev.arplant.55.031903.141610.

Malyshev, S., E. Shevliakova, R. J. Stouffer, \& S. W. Pacala (2015), Contrasting Local versus Regional Effects of Land-Use-Change-Induced Heterogeneity on Historical Climate:

Analysis with the GFDL Earth System Model, J. Clim., 28(13), 5448-5469, doi: 10.1175/JcliD-14-00586.1. 
Manes, F., M. Vitale, A. M. Fabi, F. De Santis, \& D. Zona (2007), Estimates of potential ozone stomatal uptake in mature trees of Quercus ilex in a Mediterranean climate, Environ Exp Bot, 59(2), 235-241, doi: 10.1016/j.envexpbot.2005.12.001.

Matsuda, K., I. Watanabe, \& V. Wingpud (2005), Ozone dry deposition above a tropical forest in the dry season in northern Thailand, Atmos. Environ., 39(14), 2571-2577, doi: 10.1016/j.atmosenv.2005.01.011.

Matsuda, K., I. Watanabe, V. Wingpud, P. Theramongkol, \& T. Ohizumi (2006), Deposition velocity of O-3 and SO2 in the dry and wet season above a tropical forest in northern Thailand, Atmos. Environ., 40(39), 7557-7564, doi: 10.1016/j.atmosenv.2006.07.003.

Mereu, S., E. Salvatori, L. Fusaro, G. Gerosa, B. Muys, \& F. Manes (2009), An integrated approach shows different use of water resources from Mediterranean maquis species in a coastal dune ecosystem, Biogeosciences, 6(11), 2599-2610, doi: 10.5194/bg-6-2599-2009.

Meyers, T. P., P. Finkelstein, J. Clarke, T. G. Ellestad, \& P. F. Sims (1998), A multilayer model for inferring dry deposition using standard meteorological measurements, J. Geophys. Res.-Atmos., 103(D17), 22645-22661, doi: 10.1029/98jd01564.

Mikkelsen, T. N., H. Ro-Poulsen, M. F. Hovmand, N. O. Jensen, K. Pilegaard, \& A. H. Egelov (2004), Five-year measurements of ozone fluxes to a Danish Norway spruce canopy, Atmos. Environ., 38(15), 2361-2371, doi: 10.1016/j.atmosenv.2003.12.036.

Milly, P. C. D., S. L. Malyshev, E. Shevliakova, K. A. Dunne, K. L. Findell, T. Gleeson, et al. (2014), An Enhanced Model of Land Water and Energy for Global Hydrologic and EarthSystem Studies, J Hydrometeorol, 15(5), 1739-1761, doi: 10.1175/Jhm-D-13-0162.1.

Morgenstern, O., M. I. Hegglin, E. Rozanov, F. M. O'Connor, N. L. Abraham, H. Akiyoshi, et al. (2017), Review of the global models used within phase 1 of the Chemistry-Climate Model Initiative (CCMI), Geosci Model Dev, 10(2), 639-671, doi: 10.5194/gmd-10-6392017.

Nasrollahi, N., A. AghaKouchak, L. Y. Cheng, L. Damberg, T. J. Phillips, C. Y. Miao, et al. (2015), How well do CMIP5 climate simulations replicate historical trends and patterns of meteorological droughts?, Water Resour. Res., 51(4), 2847-2864, doi:

$10.1002 / 2014 \mathrm{wr} 016318$.

Padro, J. (1996), Summary of ozone dry deposition velocity measurements and model estimates over vineyard, cotton, grass and deciduous forest in summer, Atmos. Environ., 30(13), 2363-2369, doi: 10.1016/1352-2310(95)00352-5.

Park, R. J., S. K. Hong, H. A. Kwon, S. Kim, A. Guenther, J. H. Woo, \& C. P. Loughner (2014), An evaluation of ozone dry deposition simulations in East Asia, Atmos. Chem. Phys., 14(15), 7929-7940, doi: 10.5194/acp-14-7929-2014.

Paulot, F., S. Malyshev, T. Nguyen, J. D. Crounse, E. Shevliakova, \& L. W. Horowitz (2018), Representing sub-grid scale variations in nitrogen deposition associated with land use in a global Earth System Model: implications for present and future nitrogen deposition fluxes over North America, Atmos. Chem. Phys., 18, 17963-17978, doi: 10.5194/acp-1817963-2018. 
Pilegaard, K., N. O. Jensen, \& P. Hummelshoj (1995), Seasonal and diurnal variation in the deposition velocity of ozone over a spruce forest in Denmark, Water Air Soil Poll, 85(4), 2223-2228, doi: 10.1007/Bf01186164.

Rannik, U., N. Altimir, I. Mammarella, J. Back, J. Rinne, T. M. Ruuskanen, et al. (2012), Ozone deposition into a boreal forest over a decade of observations: evaluating deposition partitioning and driving variables, Atmos. Chem. Phys., 12(24), 12165-12182, doi: 10.5194/acp-12-12165-2012.

Rummel, U., C. Ammann, G. A. Kirkman, M. A. L. Moura, T. Foken, M. O. Andreae, \& F. X. Meixner (2007), Seasonal variation of ozone deposition to a tropical rain forest in southwest Amazonia, Atmos. Chem. Phys., 7(20), 5415-5435, doi: 10.5194/acp-7-5415-2007.

Rydsaa, J. H., F. Stordal, G. Gerosa, A. Finco, \& O. Hodnebrog (2016), Evaluating stomatal ozone fluxes in WRF-Chern: Comparing ozone uptake in Mediterranean ecosystems, Atmos. Environ., 143, 237-248, doi: 10.1016/j.atmosenv.2016.08.057.

Schultz, M. G., S. Schroder, O. Lyapina, O. R. Cooper, I. Galbally, I. Petropavlovskikh, et al. (2017), Tropospheric Ozone Assessment Report: Database and metrics data of global surface ozone observations, Elementa-Sci Anthrop, 5, doi: 10.1525/elementa.244.

Seneviratne, S. I., D. Luthi, M. Litschi, \& C. Schar (2006), Land-atmosphere coupling and climate change in Europe, Nature, 443(7108), 205-209, doi: 10.1038/nature05095.

Sentman, L. T., E. Shevliakova, R. J. Stouffer, \& S. Malyshev (2011), Time Scales of Terrestrial Carbon Response Related to Land-Use Application: Implications for Initializing an Earth System Model, Earth Interact, 15, doi: 10.1175/2011ei401.1.

Sheffield, J., G. Goteti, \& E. F. Wood (2006), Development of a 50-year high-resolution global dataset of meteorological forcings for land surface modeling, J. Clim., 19(13), 30883111, doi: $10.1175 / \mathrm{Jcli3} 390.1$.

Shepherd, T. G. (2014), Atmospheric circulation as a source of uncertainty in climate change projections, Nat. Geosci., 7(10), 703-708, doi: 10.1038/Ngeo2253.

Shevliakova, E., S. W. Pacala, S. Malyshev, G. C. Hurtt, P. C. D. Milly, J. P. Caspersen, et al. (2009), Carbon cycling under 300 years of land use change: Importance of the secondary vegetation sink, Global Biogeochem. Cycles, 23, doi: 10.1029/2007gb003176.

Silva, S. J., \& C. L. Heald (2018), Investigating Dry Deposition of Ozone to Vegetation, J. Geophys. Res.-Atmos., 123(1), 559-573, doi: 10.1002/2017jd027278.

Simpson, D., A. Benedictow, H. Berge, R. Bergstrom, L. D. Emberson, H. Fagerli, et al. (2012), The EMEP MSC-W chemical transport model - technical description, Atmos. Chem. Phys., 12(16), 7825-7865, doi: 10.5194/acp-12-7825-2012.

Sitch, S., P. M. Cox, W. J. Collins, \& C. Huntingford (2007), Indirect radiative forcing of climate change through ozone effects on the land-carbon sink, Nature, 448(7155), 791-U794, doi: 10.1038/nature06059. 
Stella, P., E. Personne, B. Loubet, E. Lamaud, E. Ceschia, P. Beziat, et al. (2011), Predicting and partitioning ozone fluxes to maize crops from sowing to harvest: the Surfatm-O-3 model, Biogeosciences, 8(10), 2869-2886, doi: 10.5194/bg-8-2869-2011.

Stevenson, D. S., F. J. Dentener, M. G. Schultz, K. Ellingsen, T. P. C. van Noije, O. Wild, et al. (2006), Multimodel ensemble simulations of present-day and near-future tropospheric ozone, J. Geophys. Res., 111(D8), doi: 10.1029/2005jd006338.

Travis, K. R., D. J. Jacob, J. A. Fisher, P. S. Kim, E. A. Marais, L. Zhu, et al. (2016), Why do models overestimate surface ozone in the Southeast United States?, Atmos. Chem. Phys., 16, 13561-13577, doi: 10.5194/acp-16-13561-2016.

Turnipseed, A. A., S. P. Burns, D. J. P. Moore, J. Hu, A. B. Guenther, \& R. K. Monson (2009), Controls over ozone deposition to a high elevation subalpine forest, Agr Forest Meteorol, 149(9), 1447-1459, doi: 10.1016/j.agrformet.2009.04.001.

Ukkola, A, M., A. J. Pitman, M. G. De Kauwe, G. Abramowitz, N. Herger, J. P. Evans, \& M. Decker (2018), Evaluating CMIP5 Model Agreement for Multiple Drought Metrics, J Hydrometeorol, 19(6), 969-988, doi: 10.1175/Jhm-D-17-0099.1.

Val Martin, M., C. L. Heald, \& S. R. Arnold (2014), Coupling dry deposition to vegetation phenology in the Community Earth SystemModel: Implications for the simulation of surface O3, Geophys. Res. Lett., 41(8), 2988-2996, doi: 10.1002/2014GL059651.

Weng, E. S., S. Malyshev, J. W. Lichstein, C. E. Farrior, R. Dybzinski, T. Zhang, et al. (2015), Scaling from individual trees to forests in an Earth system modeling framework using a mathematically tractable model of height-structured competition, Biogeosciences, 12(9), 2655-2694, doi: 10.5194/bg-12-2655-2015.

Wesely, M. L. (1989), Parameterization of surface resistances to gaseous dry deposition in regional-scale numerical models, Atmos. Environ., 23, 1293-1304, doi:

https://doi.org/10.1016/0004-6981(89)90153-4.

Wesely, M. L., \& B. B. Hicks (2000), A review of the current status of knowledge on dry deposition, Atmos. Environ., 34(12-14), 2261-2282, doi: 10.1016/S1352-2310(99)00467-7.

Wild, O. (2007), Modelling the global tropospheric ozone budget: exploring the variability in current models, Atmos. Chem. Phys., 7(10), 2643-2660, doi: 10.5194/acp-7-2643-2007.

Wu, Z. Y., L. Zhang, X. M. Wang, \& J. W. Munger (2015), A modified micrometeorological gradient method for estimating O-3 dry depositions over a forest canopy, Atmos. Chem. Phys., 15(13), 7487-7496, doi: 10.5194/acp-15-7487-2015.

Wu, Z. Y., R. Staebler, R. Vet, \& L. M. Zhang (2016), Dry deposition of O3 and SO2 estimated from gradient measurements above a temperate mixed forest, Environ. Pollut., 210, 202-210, doi: 10.1016/j.envpol.2015.11.052.

Wu, Z. Y., D. Schwede, R. Vet, J. T. Walker, M. Shaw, R. Staebler, \& L. Zhang (2018), Evaluation and intercomparison of five major dry deposition algorithms in North America, Journal of Advances in Modeling Earth Systems, doi: 10.1029/2017MS001231. 
Young, P. J., V. Naik, A. M. Fiore, A. Gaudel, J. Guo, M. Y. Lin, et al. (2018), Tropospheric Ozone Assessment Report: Assessment of global-scale model performance for global and regional ozone distributions, variability, and trends, Elementa-Sci Anthrop, 6, doi: 10.1525/elementa.265.

Young, P. J., A. T. Archibald, K. W. Bowman, J. F. Lamarque, V. Naik, D. S. Stevenson, et al. (2013), Pre-industrial to end 21st century projections of tropospheric ozone from the Atmospheric Chemistry and Climate Model Intercomparison Project (ACCMIP), Atmos. Chem. Phys., 13(4), 2063-2090, doi: 10.5194/acp-13-2063-2013.

Zapletal, M., P. Cudlin, P. Chroust, O. Urban, R. Pokorny, M. Edwards-Jonasova, et al. (2011), Ozone flux over a Norway spruce forest and correlation with net ecosystem production, Environ. Pollut., 159(5), 1024-1034, doi: 10.1016/j.envpol.2010.11.037.

Zhang, L. M., J. R. Brook, \& R. Vet (2002), On ozone dry deposition - with emphasis on non-stomatal uptake and wet canopies, Atmos. Environ., 36(30), 4787-4799, doi: 10.1016/S1352-2310(02)00567-8.

Zhang, L. M., J. R. Brook, \& R. Vet (2003), A revised parameterization for gaseous dry deposition in air-quality models, Atmos. Chem. Phys., 3, 2067-2082, doi: 10.5194/acp-32067-2003.

Zhang, L. M., R. Vet, J. R. Brook, \& A. H. Legge (2006), Factors affecting stomatal uptake of ozone by different canopies and a comparison between dose and exposure, Sci. Total Environ., 370(1), 117-132, doi: 10.1016/j.scitotenv.2006.06.004.

Zhao, M., J. C. Golaz, I. M. Held, H. Guo, V. Balaji, R. Benson, et al. (2018a), The GFDL Global Atmosphere and Land Model AM4.0/LM4.0:1. Simulation Characteristics With Prescribed SSTs, Journal of Advances in Modeling Earth Systems, 10(3), 691-734, doi: $10.1002 / 2017 \mathrm{~ms} 001208$.

Zhao, M., J. C. Golaz, I. M. Held, H. Guo, V. Balaji, R. Benson, et al. (2018b), The GFDL Global Atmosphere and Land Model AM4.0/LM4.0:2. Model Description, Sensitivity Studies, and Tuning Strategies, Journal of Advances in Modeling Earth Systems, 10(3), 735769, doi: 10.1002/2017ms001209. 
Table 1: Characteristics of the $V_{d, 03}$ measurement sites

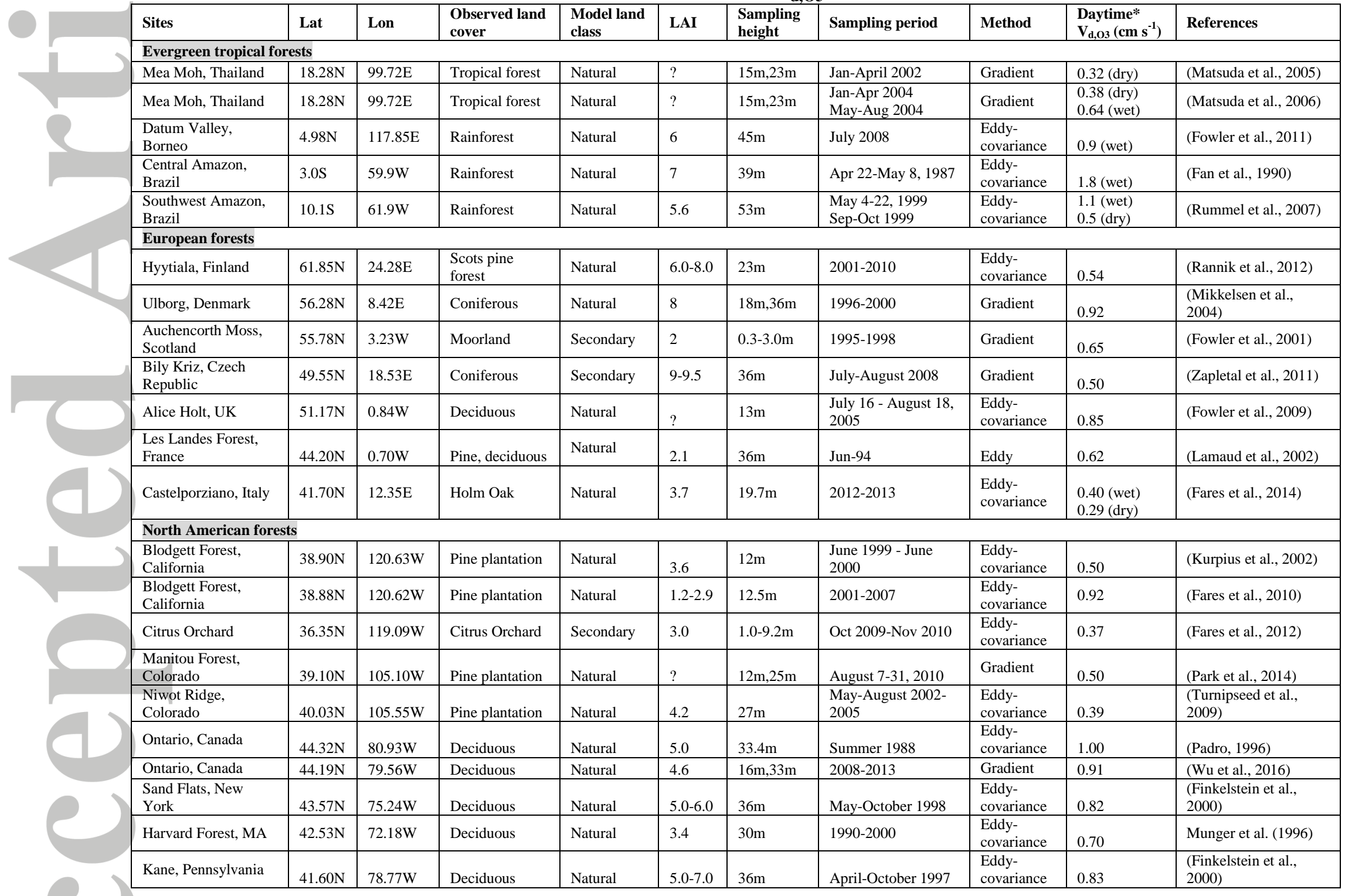

(C) 2019 American Geophysical Union. All rights reserved. 


\begin{tabular}{|c|c|c|c|c|c|c|c|c|c|c|}
\hline \multicolumn{11}{|l|}{ Croplands } \\
\hline Gilchriston, Scotland & $55.90 \mathrm{~N}$ & $2.80 \mathrm{~W}$ & Potatoes & Cropland & $?$ & ? & July-August 2006 & $\begin{array}{l}\text { Eddy- } \\
\text { covariance }\end{array}$ & 0.76 & (Coyle et al., 2009) \\
\hline Grignon, France & $48.85 \mathrm{~N}$ & $1.97 \mathrm{E}$ & Maize crop & Cropland & 5.2 & $3.4 \mathrm{~m}$ & June-August 2008 & $\begin{array}{l}\text { Eddy- } \\
\text { covariance }\end{array}$ & 0.63 & (Stella et al., 2011) \\
\hline La CapeSud, France & $44.30 \mathrm{~N}$ & $0.63 \mathrm{~W}$ & Maize crop & Cropland & 5.1 & $6.4 \mathrm{~m}$ & June-August 2008 & $\begin{array}{l}\begin{array}{l}\text { Eddy- } \\
\text { covariance }\end{array} \\
\end{array}$ & 0.50 & (Stella et al., 2011) \\
\hline Lamasquere, France & $43.82 \mathrm{~N}$ & $1.38 \mathrm{E}$ & Maize crop & Cropland & 3.2 & $3.65 \mathrm{~m}$ & June-August 2008 & $\begin{array}{l}\begin{array}{l}\text { Eddy- } \\
\text { covariance }\end{array} \\
\end{array}$ & 0.38 & (Stella et al., 2011) \\
\hline Bondville, Illinois & $40.05 \mathrm{~N}$ & $88.37 \mathrm{~W}$ & Corn & Cropland & $2.4-3$ & ? & $\begin{array}{l}\text { August 18-October } \\
1,1994\end{array}$ & $\begin{array}{l}\text { Eddy- } \\
\text { covariance }\end{array}$ & 0.6 & (Meyers et al., 1998) \\
\hline Nashville, Tennesse & $36.65 \mathrm{~N}$ & $87.03 \mathrm{~W}$ & Soybeans & Cropland & $1.0-6.0$ & $4.55 \mathrm{~m}$ & $\begin{array}{l}\text { June 22-October } \\
11,1995\end{array}$ & $\begin{array}{l}\begin{array}{l}\text { Eddy- } \\
\text { covariance }\end{array} \\
\end{array}$ & 0.7 & (Meyers et al., 1998) \\
\hline \multicolumn{11}{|l|}{ Grassland/Pasture } \\
\hline Mean of 11 datasets & & & & Pasture & & & & & 0.4 & $\begin{array}{l}\text { (Silva \& Heald, 2018) } \\
\text { and references therein }\end{array}$ \\
\hline
\end{tabular}

* For evergreen tropical forests. 9AM-3PM average values in $\mathrm{cm} \mathrm{s}^{-1}$ are reported for the dry and wet seasons, respectively. For the other vegetation types, only the daytime values for the growing season (June-JulyAugust) are reported. The ? mark indicates that the information was not reported in the literature.

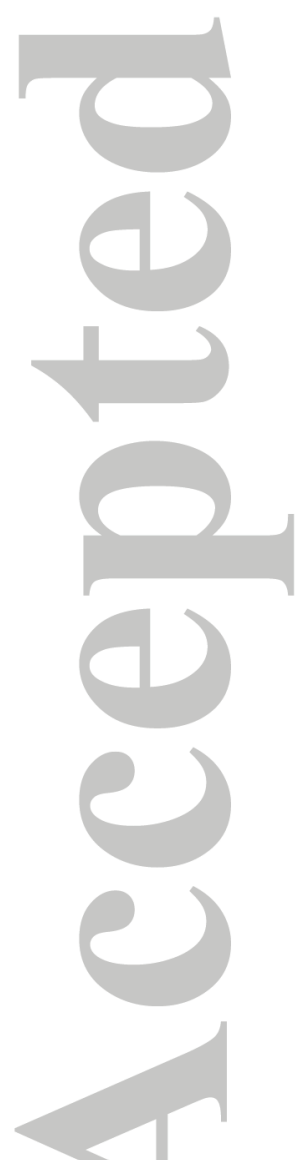




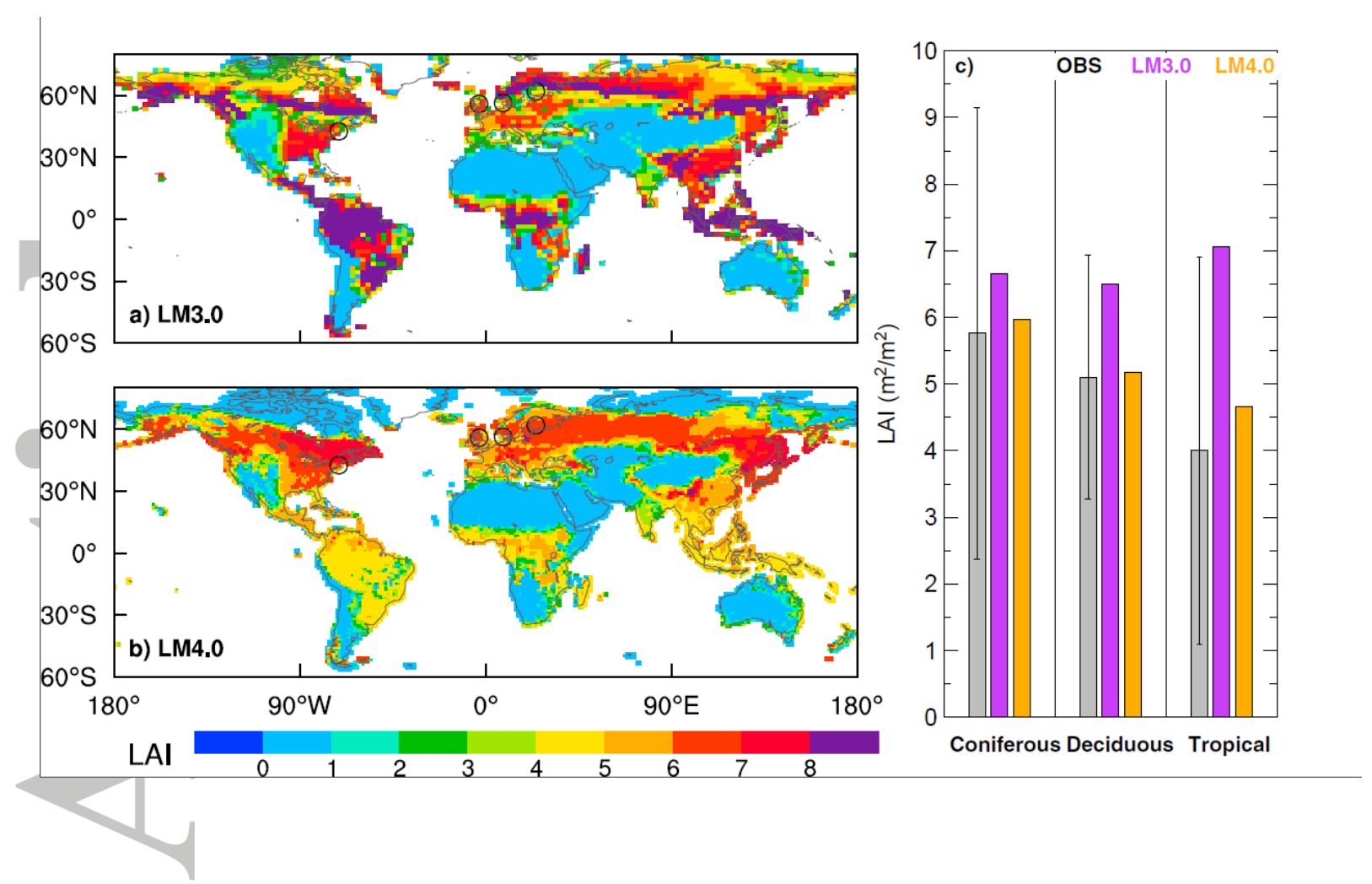

Figure 1. (a-b) Maps of June-July-August (JJA) average LAI (1990-2014) for natural forests in GFDL LM3.0 and LM4.0. The black circles denote locations of ozone deposition velocity $\left(\mathrm{V}_{\mathrm{d}, \mathrm{O}}\right)$ measurement sites at Hyytiala Finland, Auchencorth Moss Scotland, Ulborg Denmark, and Harvard Forest USA (see Figs. 2 and 3). (c) Comparisons of LAI for evergreen coniferous forest, deciduous broadleaf forest, and evergreen tropical forest derived from field-based measurements (Iio and Ito, 2014) with model results. 


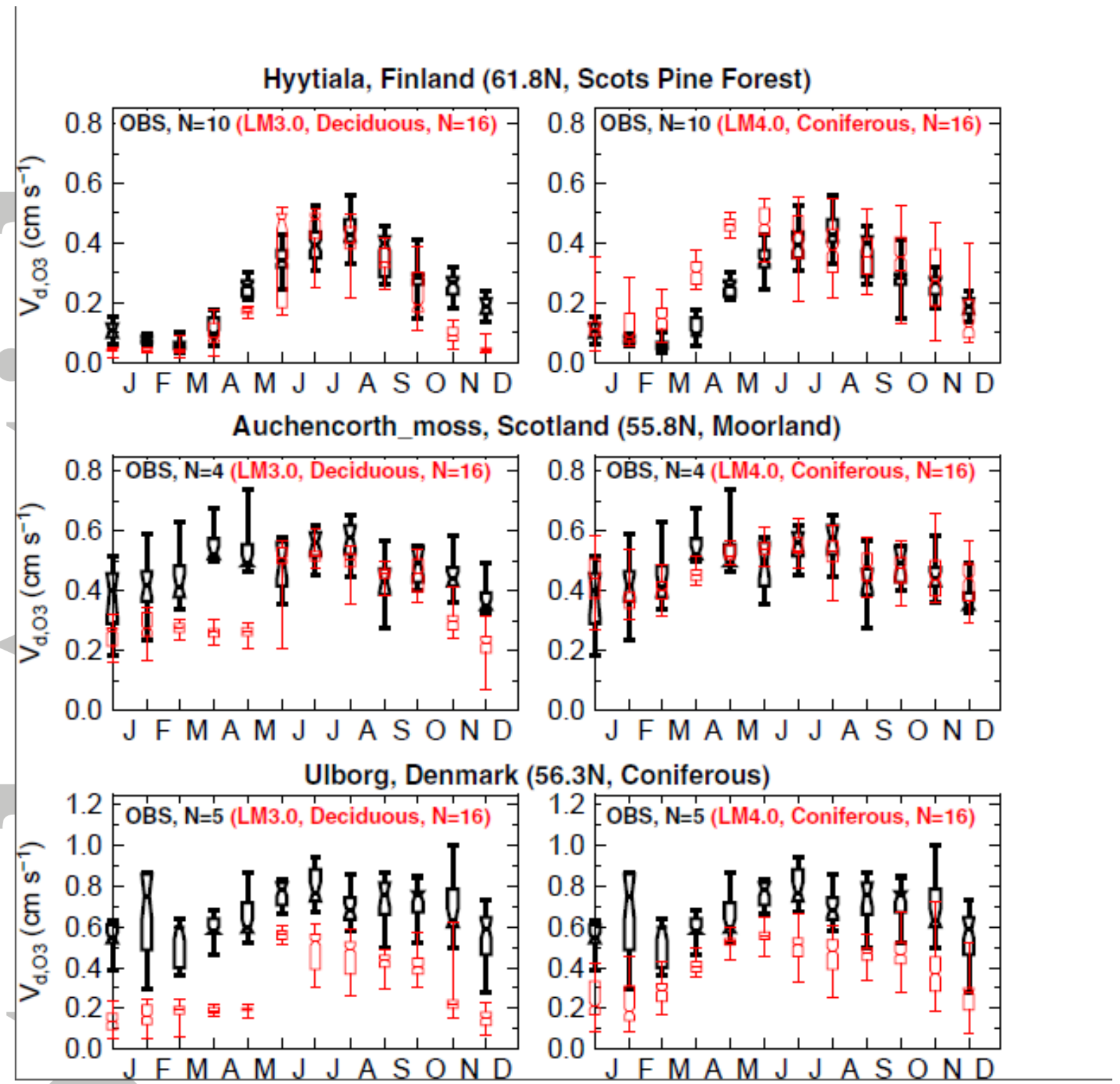

Figure 2. Comparisons of monthly 24-hr mean $\mathrm{V}_{\mathrm{d}, \mathrm{O}}$ at north European forest sites as observed (black) and simulated (red) by GFDL LM3.0 (left) and LM4.0 (right). Here and in other figures, the box-andwhisker plots give the minimum, 25th-75th percentiles and maximum of monthly average values over the measurement periods (Table 1) and for the model period 1995-2010. $\mathrm{N}$ indicates the number of years. 
Harvard Forest, U.S. (Deciduous), $\mathrm{N}=11$
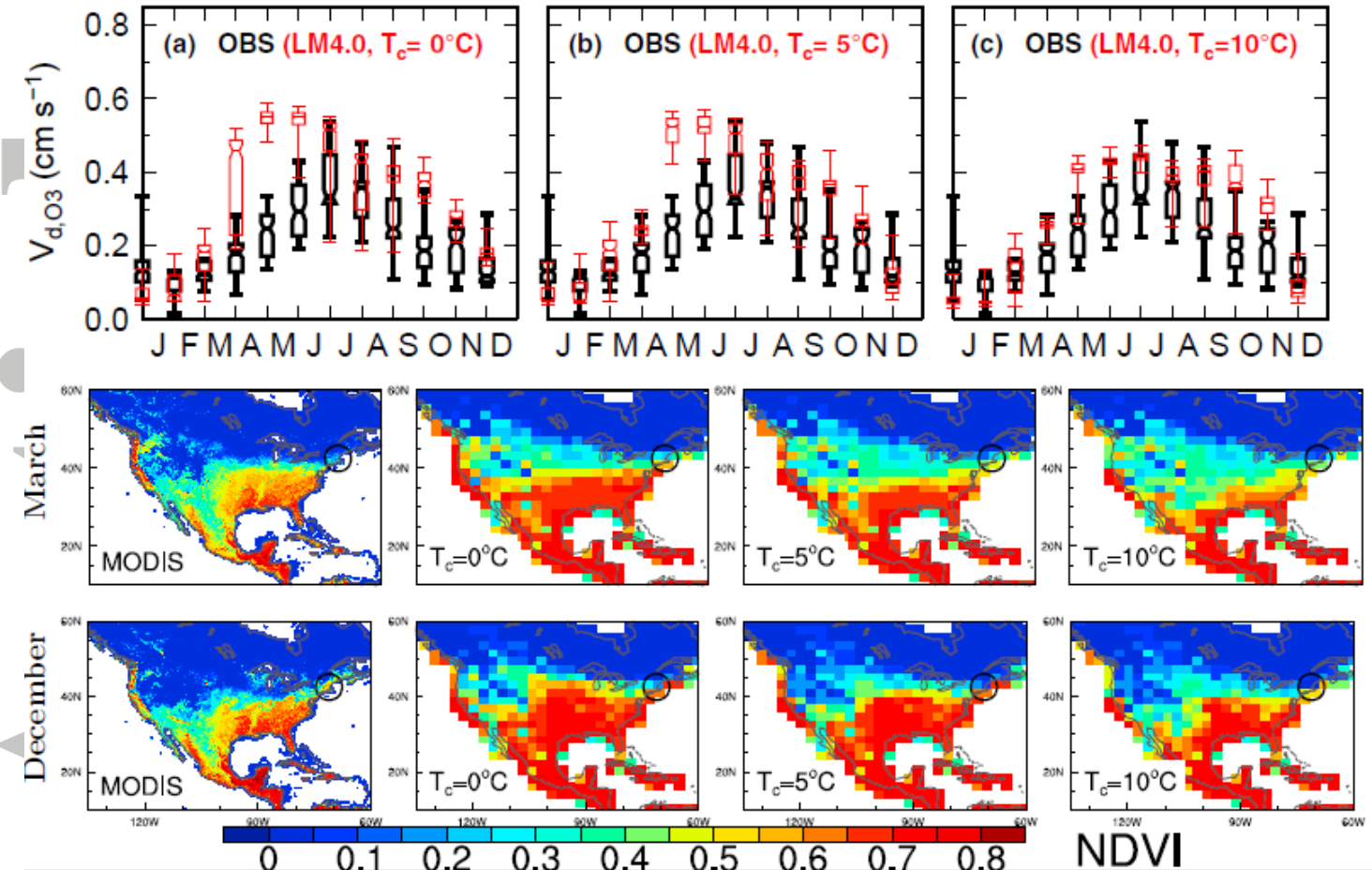

Figure 3. (Top) Monthly 24-hr mean $\mathrm{V}_{\mathrm{d}, \mathrm{O} 3}$ at Harvard Forest from observations and LM4.0 simulations with different $\mathrm{T}_{\mathrm{c}}$ for deciduous forests. (Bottom) Maps of March and December NDVI over North America for MODIS and LM4.0 with different Tc, averaged over the 2001-2006 MODIS observation period. NDVI is computed for each month as the difference between surface NIR and VIS reflectances, divided by their sum. The black circles denote the location of Harvard Forest. 


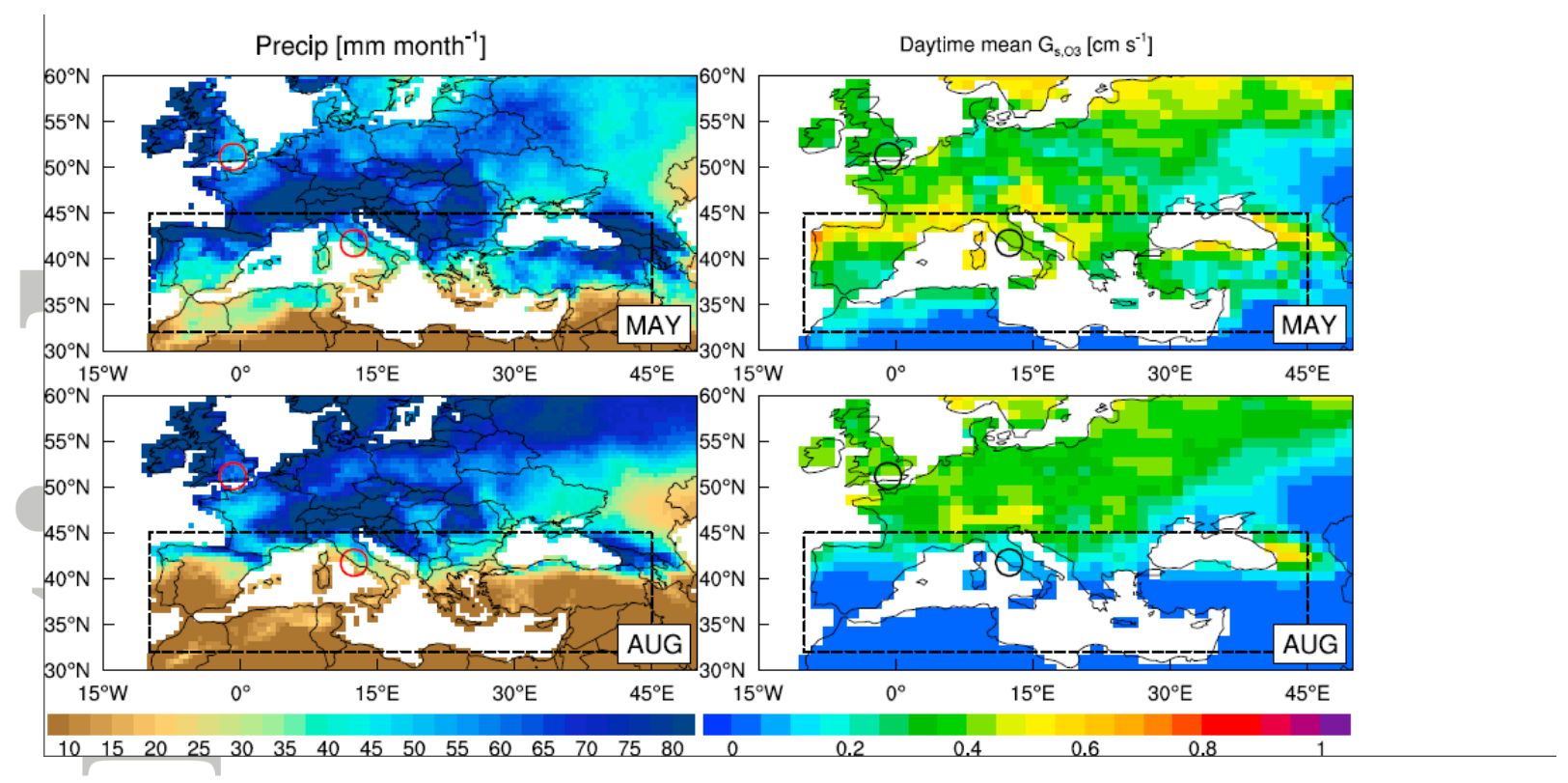

Figure 4. Maps of observed precipitation and LM4.0 simulated daytime (9am-3pm) mean stomatal conductance for $\mathrm{O}_{3}\left(\mathrm{G}_{\mathrm{s}, \mathrm{O}}\right.$, averaged over four land use categories) over Europe in May versus August over 1990-2014. The red circles denote the locations of holm oak forests at Alice Holt England and Castelporziano Italy (see Fig. 5).

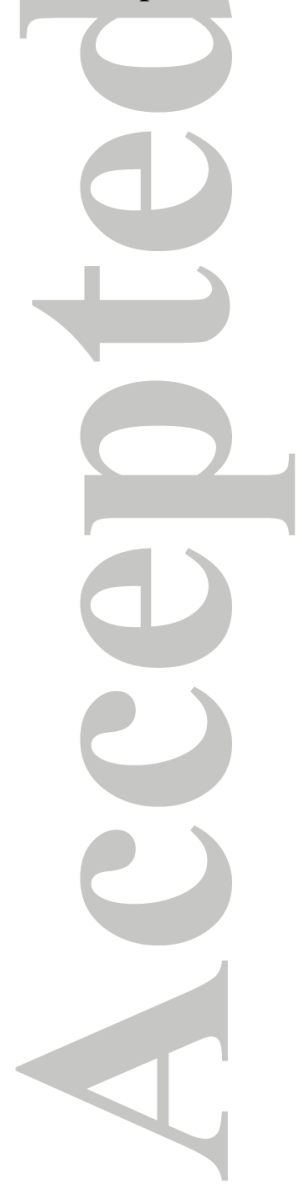


(a) Castelporziano,Italy

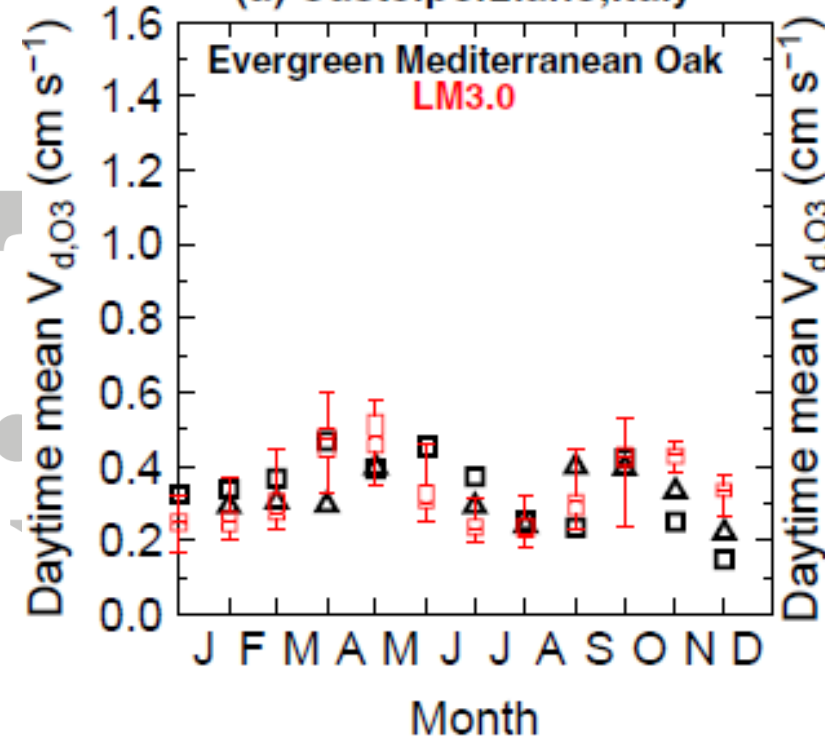

(c) Oak forest, UK Jul-Aug

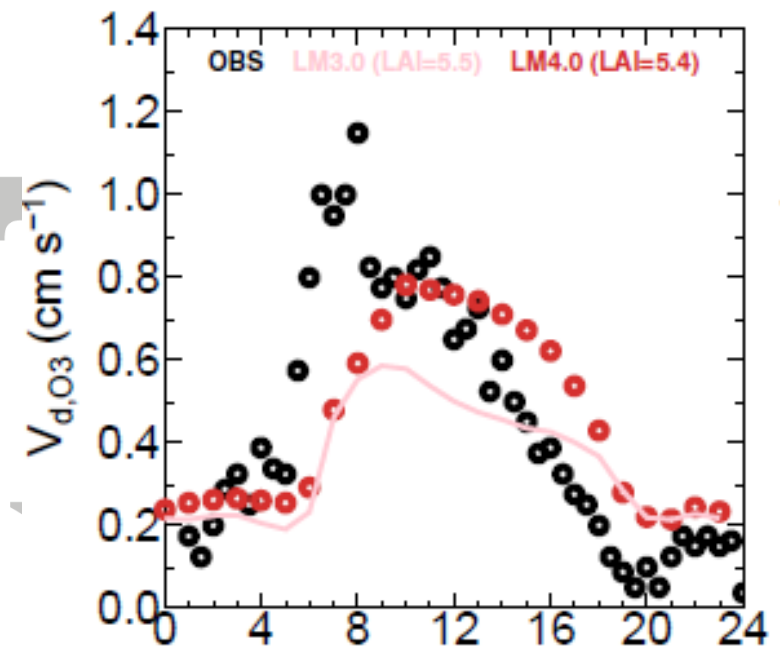

Hour (b) Castelporziano,Italy

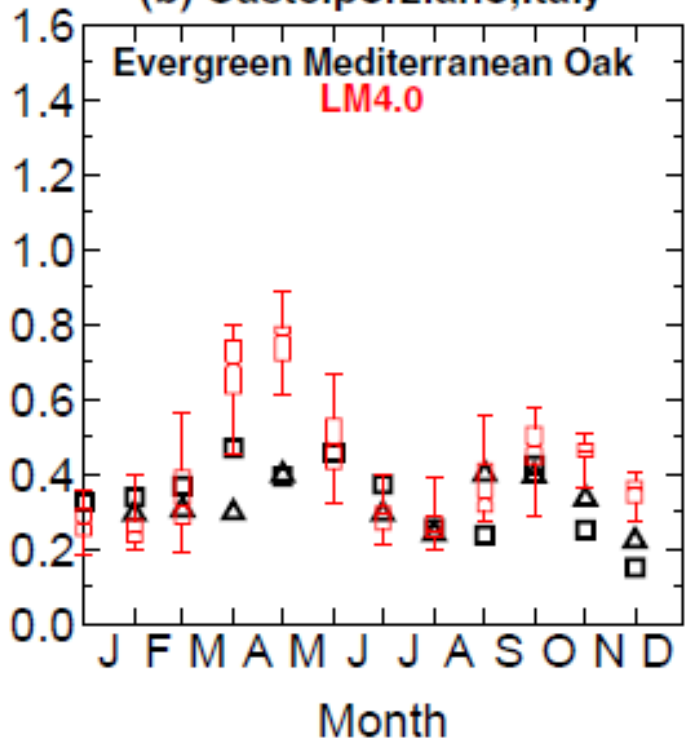

(d) Oak forest, Italy Jul-Aug

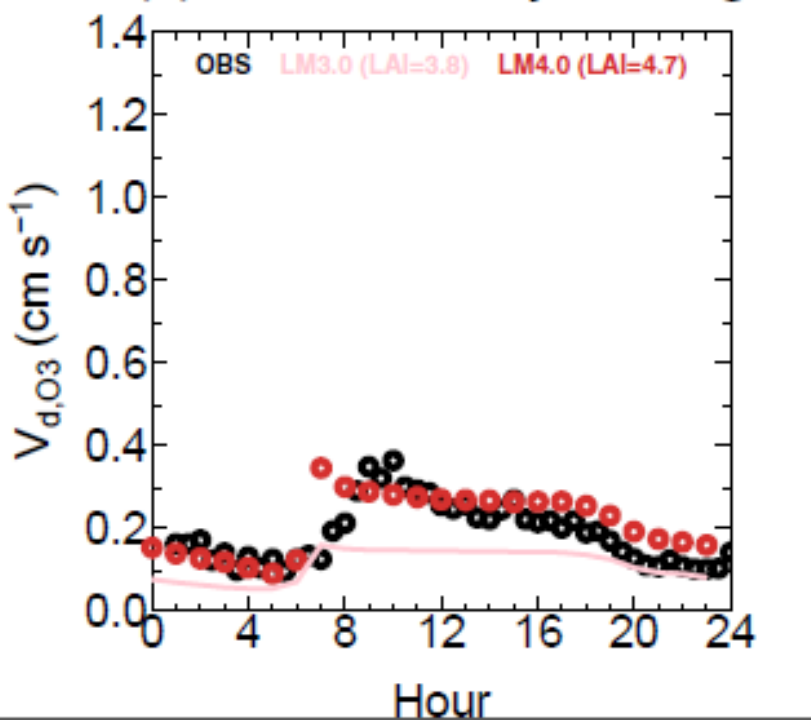

Figure 5. (a,b) Monthly daytime (9am-3pm) mean $\mathrm{V}_{\mathrm{d}, \mathrm{O}}$ at Holm oak forest, Castelporziano, Italy, derived from observations (2012-2013) and GFDL land model simulations (1990-2013). (c,d) JulyAugust mean diurnal cycle of $\mathrm{V}_{\mathrm{d}, \mathrm{O}}$ at holm oak forests in Alice Holt England versus Castelporziano Italy. 
(a) Daytime mean $\mathrm{V}_{\mathrm{d}, \mathrm{O} 3}$ to $\mathrm{crop}\left[\mathrm{cm} \mathrm{s}^{-1}\right]$
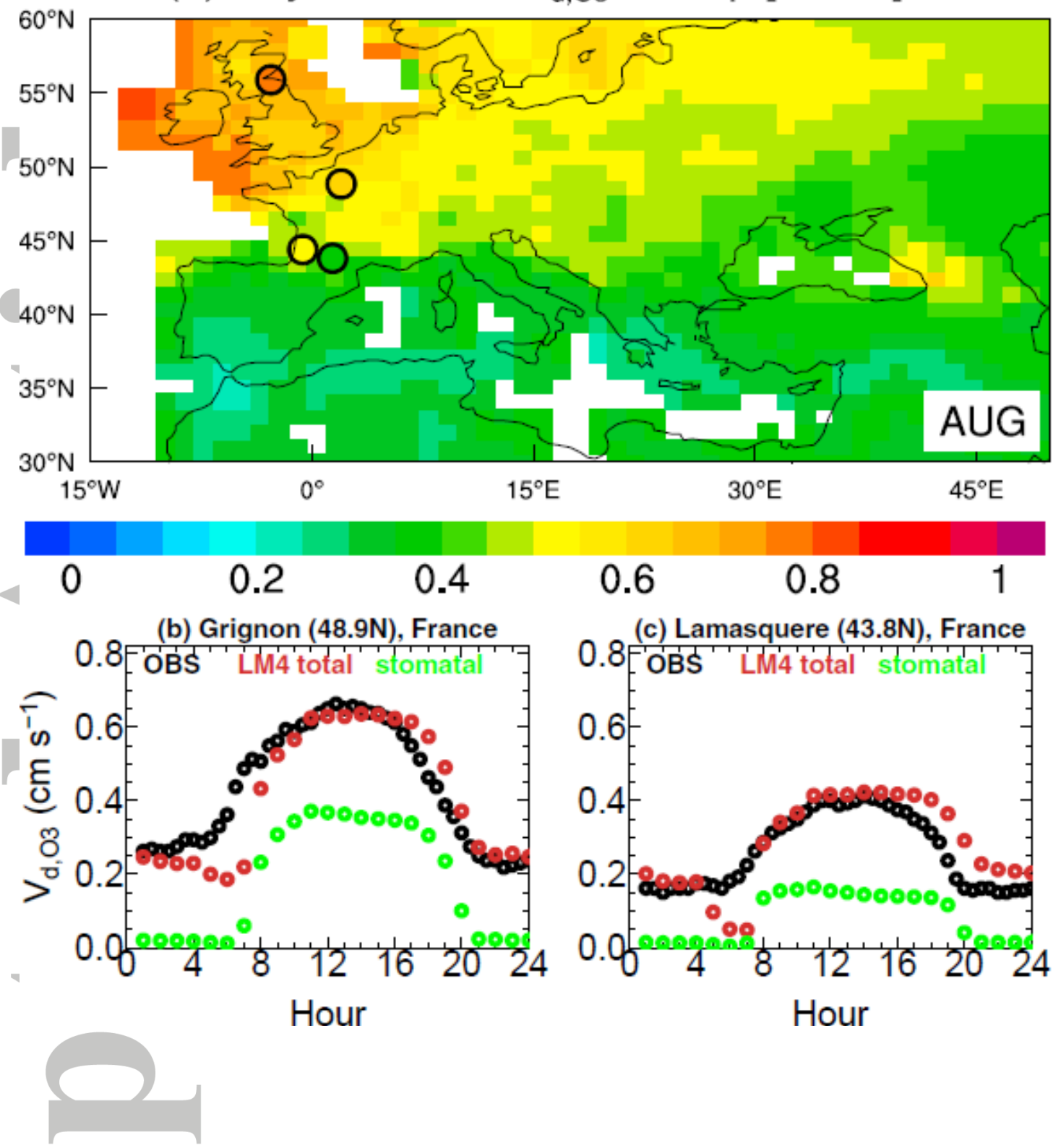

Figure 6. (a) Map of August daytime mean $\mathrm{V}_{\mathrm{d}, 03}$ to croplands over Europe in GFDL-LM4.0 (19902014). The color filled circles denote observations at potatoes, Gilchriston, Scotland (Coyle et al., 2009) and three maize crop sites in France (Stella et al., 2011). (b) Comparisons of observed and modelled diurnal cycle of $\mathrm{V}_{\mathrm{d}, \mathrm{O}}$ at maize crops in Grignon, France, Jul-Aug 2008. Both total (brown) and stomatal (green) deposition from LM4.0 are shown. (c) Same as (b) but for Lamasquere in a Mediterranean climate. 

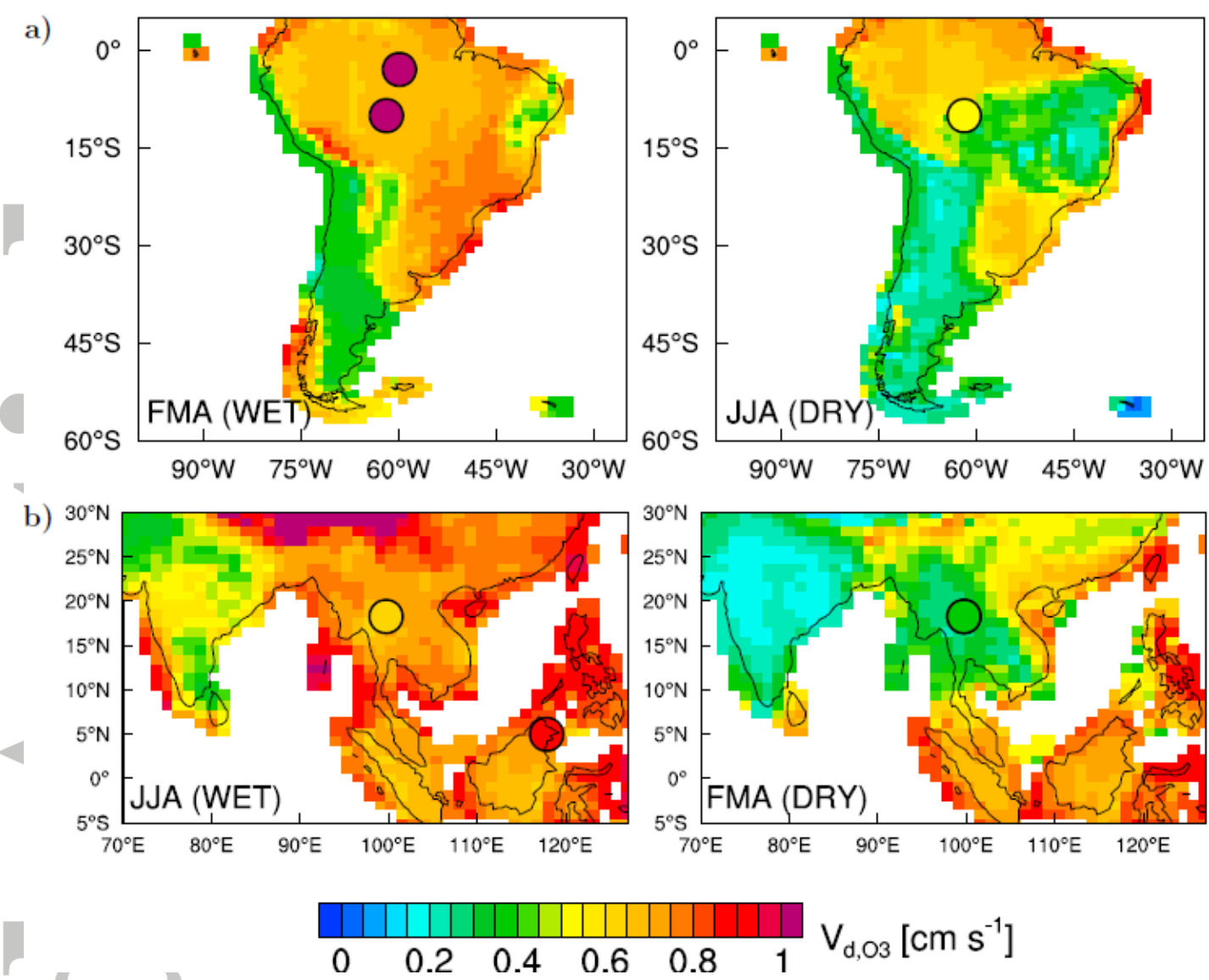

Figure 7. Influence of water availability on $\mathrm{V}_{\mathrm{d}, \mathrm{O}}$ during the wet and dry season for evergreen tropical forests in Amazon and South Asia. Shown are observed daytime mean $\mathrm{V}_{\mathrm{d}, \mathrm{O} 3}$ at measurement sites (color filled circles; see also Table 1) superimposed on maps of LM4.0 $\mathrm{V}_{\mathrm{d}, 03}$ simulations averaged over 1990-2014.

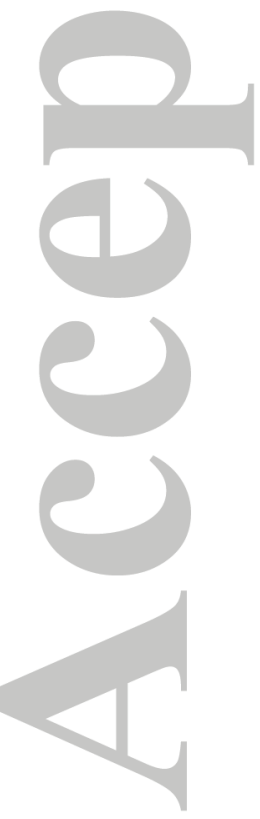



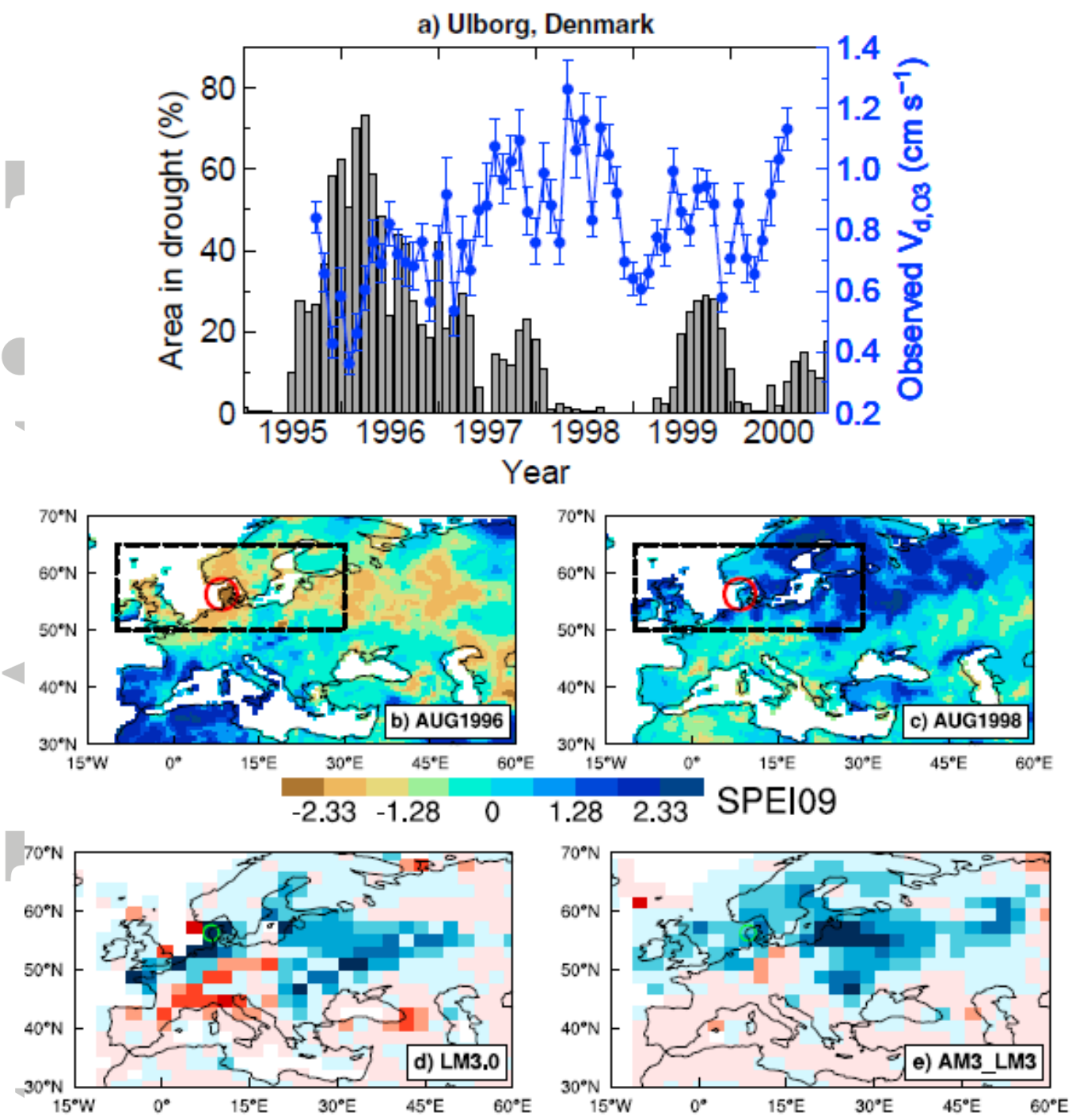

$\begin{array}{lllll}-0,4 & -0,2 & 0 & 0,2 & 0,4\end{array} \mathrm{~V}_{\mathrm{d}, 03}\left[\mathrm{~cm} \mathrm{~s}^{-1}\right]$

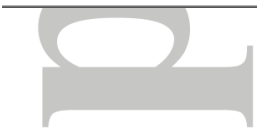

Figure 8. (a) Time series of area in drought (SPEI06 < -1.0) over Northern Europe (gray bars; box on map) and monthly daytime $(9 \mathrm{am}-3 \mathrm{pm})$ mean $\mathrm{V}_{\mathrm{d}, \mathrm{O}}$ from observations at Ulborg Denmark (blue symbols; right axis) from 1995 to 2000. Error bars in $\mathrm{V}_{\mathrm{d}, \mathrm{O}}$ indicate $95 \%$ confidence intervals estimated with a bootstrapping technique (https://www.ncl.ucar.edu/Document/Functions/Bootstrap/bootstrap_stat.shtml). (b-c) Maps of 9month (February-August) SPEI drought index over Europe for 1996 versus 1998. The 9-month SPEI (as opposed to the 6-month SPEI) is shown to highlight the prolonged feature of the 1995-1996 drought. (d-e) Anomalies in July-August daytime mean $\mathrm{V}_{\mathrm{d}, \mathrm{O} 3}$ for 1996 relative to 1998 from LM3.0 driven by observation-based meteorological forcings versus coupled with AM3 nudged to the reanalysis winds. Circles denote the location of Ulborg. 
Ontario, Canada
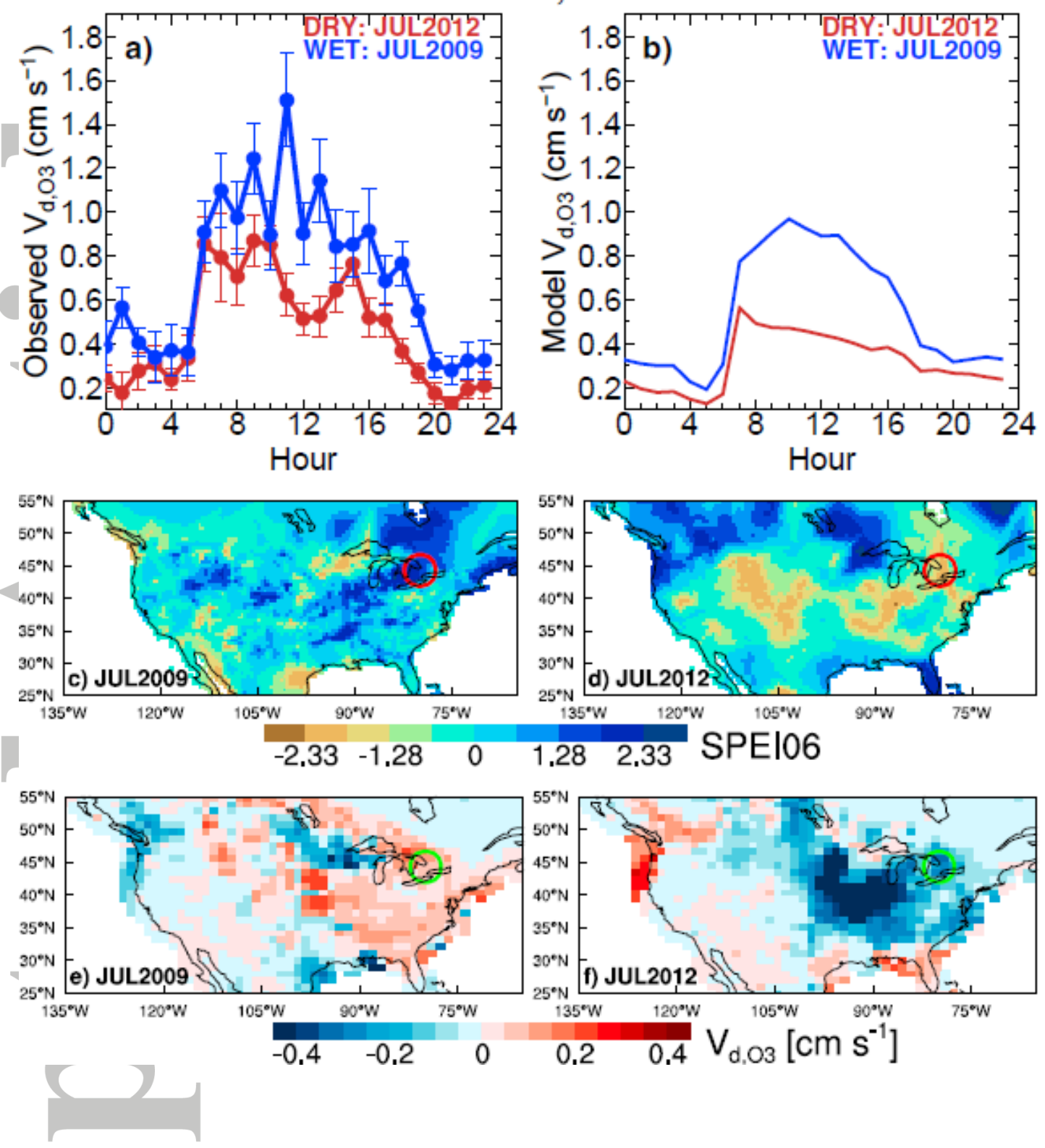

Figure 9. (a-b) Diurnal cycle of $\mathrm{V}_{\mathrm{d}, \mathrm{O} 3}$ at Borden Forest, Ontario, Canada, in July 2009 (wet) versus July 2012 (dry) derived from observations ( \pm s.d.) and from LM4.0 simulations. (c-d) Maps of 6month (February-July) SPEI drought index for 2009 versus 2012. (e-f) Maps of LM4.0 simulated anomalies (relative to 1990-2014 mean) in daytime $\mathrm{V}_{\mathrm{d}, \mathrm{O} 3}$ over forests for July 2009 and 2012. Circles on map denote the location of Borden Forest. 

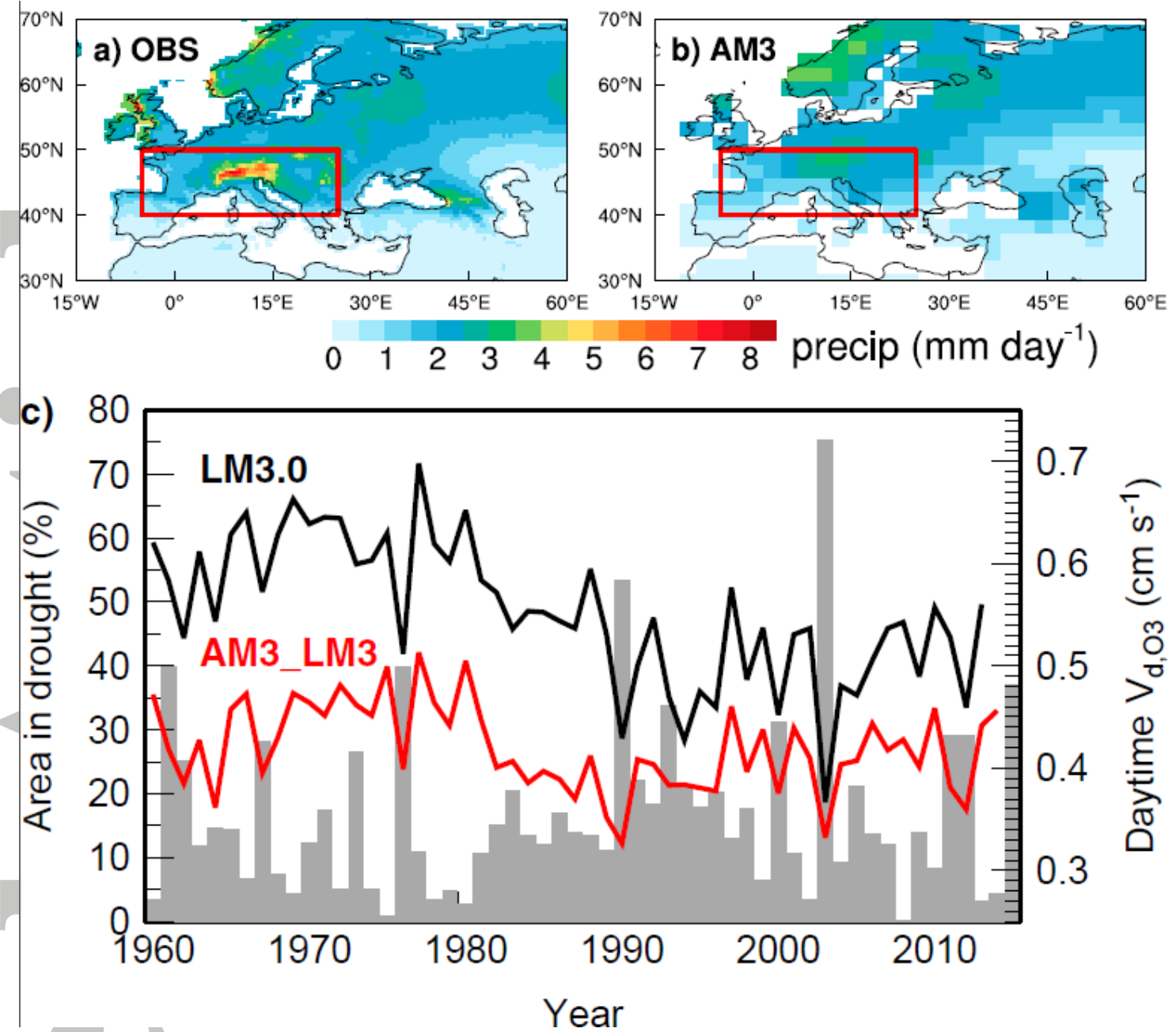

Figure 10. (a-b) JJA precipitation averaged over 1981-2010 from CRU observations and AM3 simulations. (c) Time series of JJA daytime mean $\mathrm{V}_{\mathrm{d}, \mathrm{O} 3}$ to natural forests averaged over western Europe (box on map) as simulated in LM3.0 driven by observed atmospheric forcings (black) versus coupled with AM3 (red). The gray bars indicate the percentage area of western Europe in drought derived from SPEI06 (March through August). 

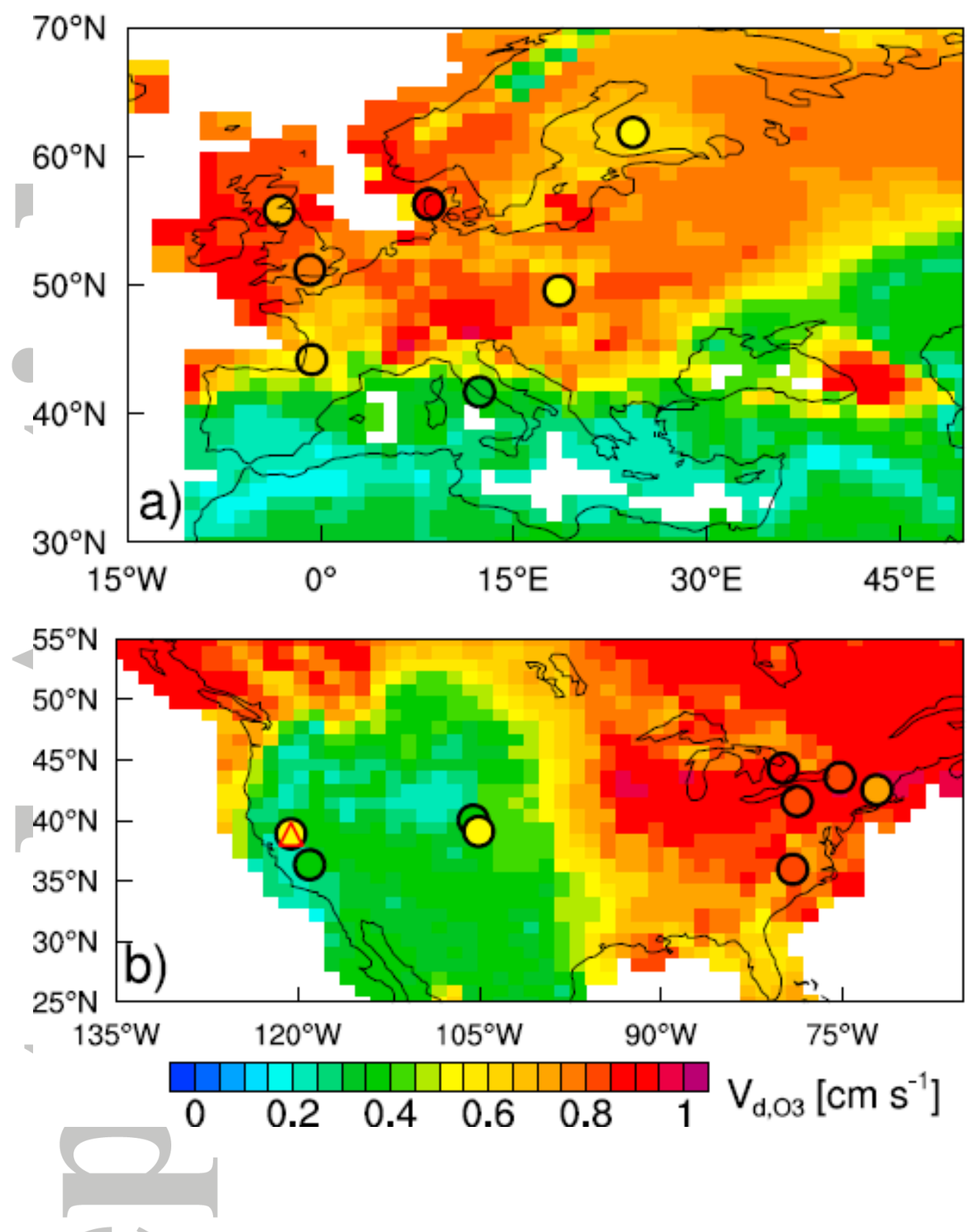

Figure 11. JJA daytime mean $\mathrm{V}_{\mathrm{d}, \mathrm{O} 3}$ to natural forests in LM4.0 (1990-2014), with the color filled symbols representing observed values at available sites (Table 1). 
(a)
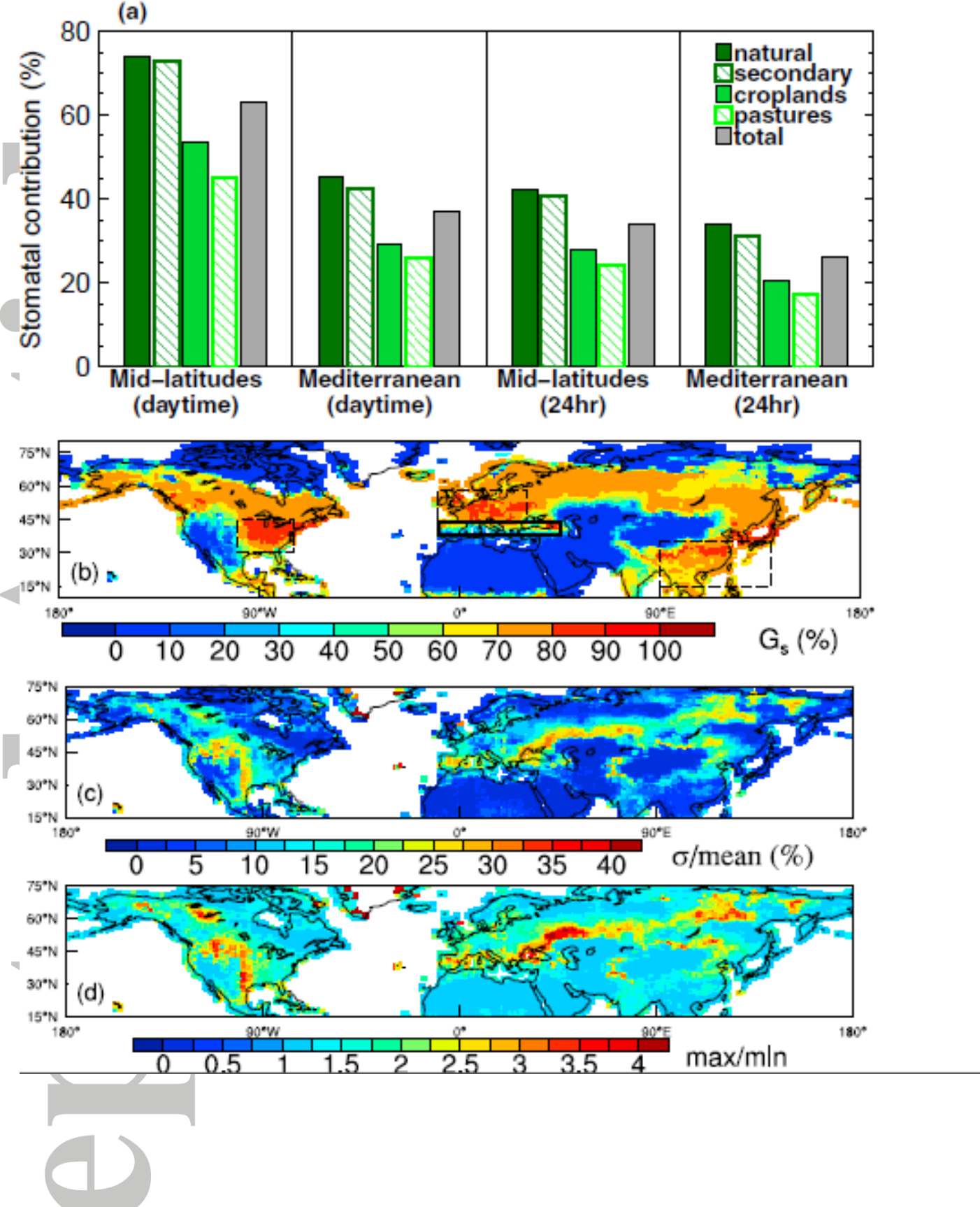

Figure 12. (a) The 1990-2014 mean stomatal fraction to the total deposition at four land use categories in LM4.0 for JJA daytime and 24-hour means, respectively, over northern mid-latitude regions (dashed boxes on map) versus over the semi-arid Mediterranean region (solid box). (b) Map of the JJA daytime mean stomatal fraction for forests (see Text S3 for the diagnostic method). (c) Map of the relative standard deviation from the mean of JJA daytime $\mathrm{V}_{\mathrm{d}, \mathrm{O}}$ for forests and (d) the ratio of maximum and minimum values across the period 1980-2014.

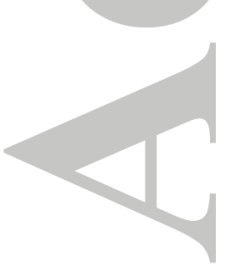




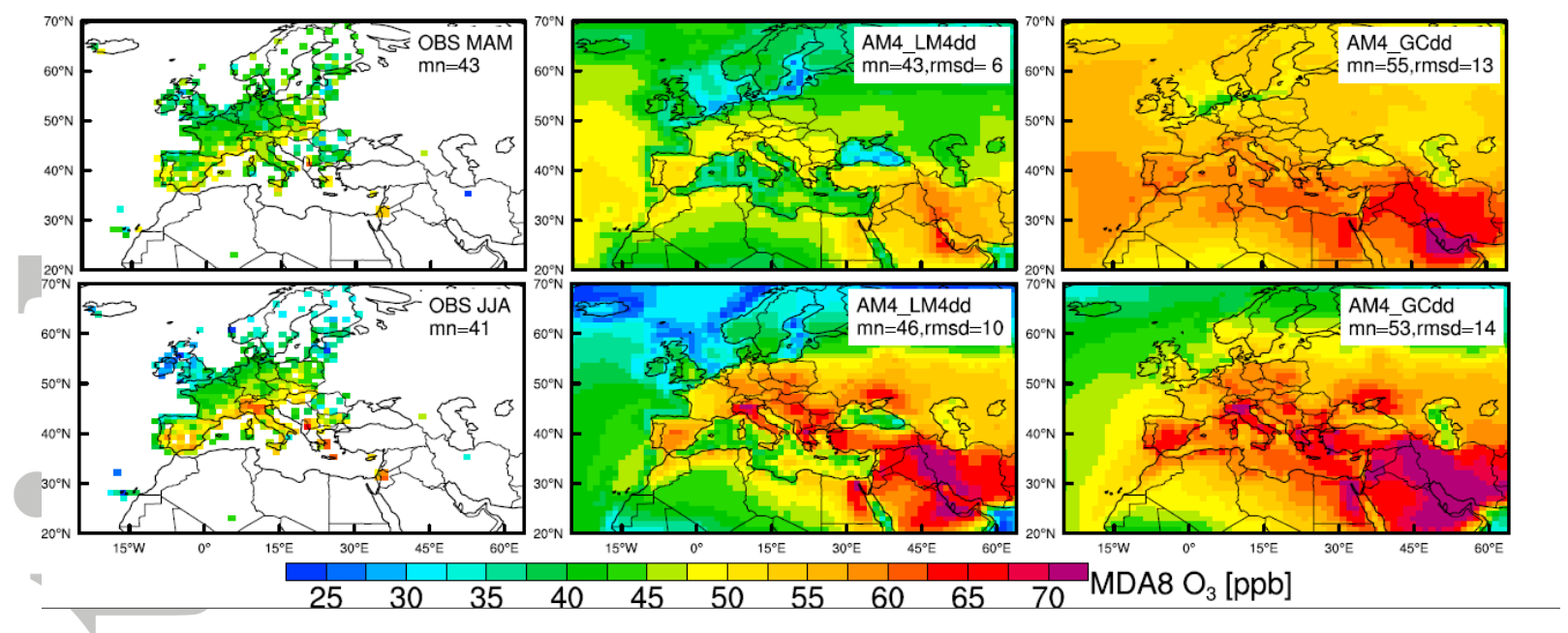

Figure 13. MAM and JJA mean surface MDA8 O3 mixing ratios over Europe averaged over 20052014 from TOAR observations and AM4 simulations with Vd,O3 from GFDL-LM4.0 (AM4_LM4dd) versus from the Wesely scheme as implemented in GEOS-Chem (AM4_GCdd). Here and in other figures, $\mathrm{mn}$ is the mean and rmsd is the root-mean-square deviation between observations and simulations.

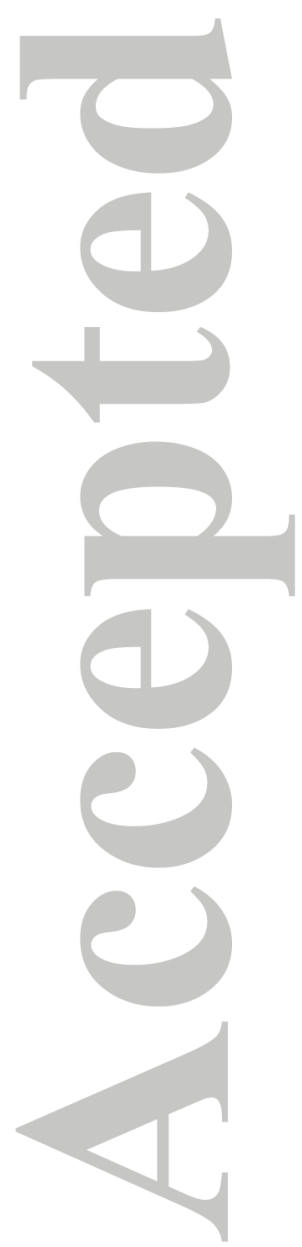



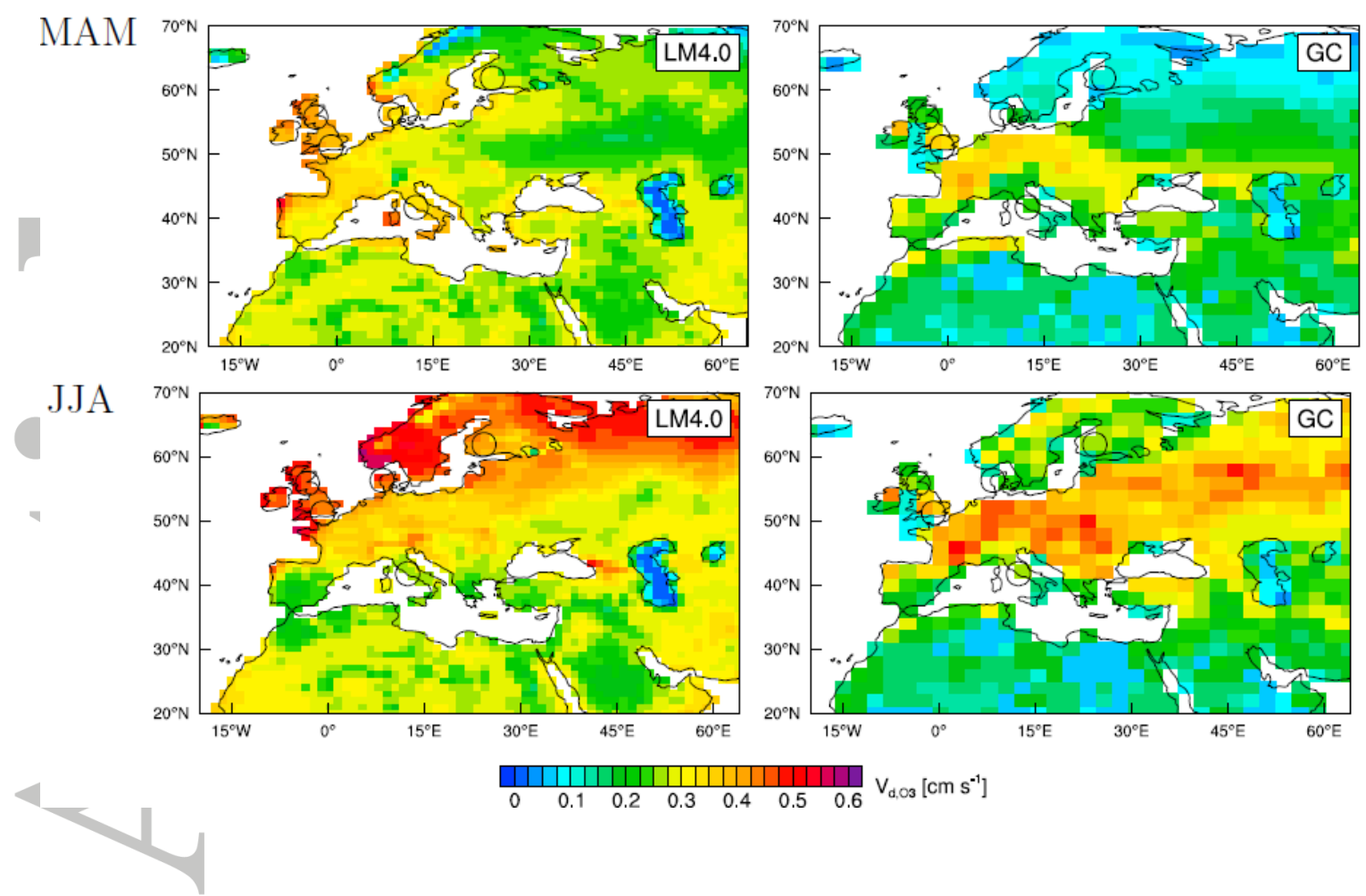

Figure 14. MAM and JJA 24-hr mean Vd,O3 over Europe from GFDL-LM4.0 versus from the Wesely scheme as implemented in GEOS-Chem (2005-2014 average). The circles denote the locations of $\mathrm{Vd}, \mathrm{O} 3$ measurement sites to facilitate comparisons with data shown in Figs. 2 and 5. 


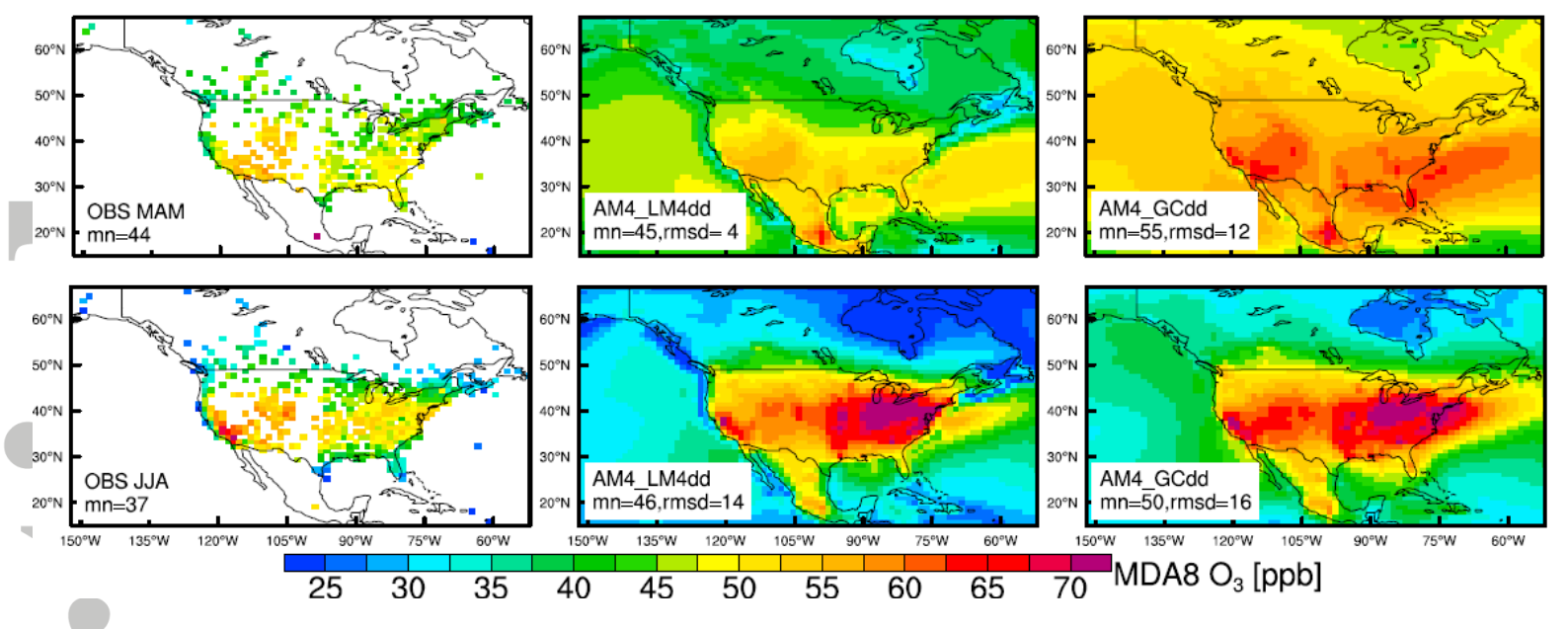

Figure 15. Same as Fig. 13 but for North America. 

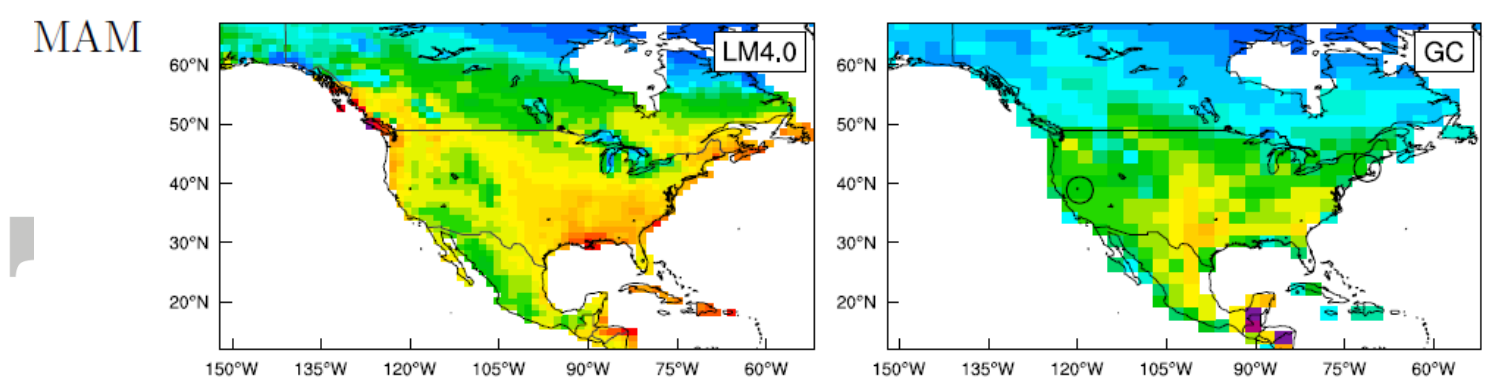

JJA
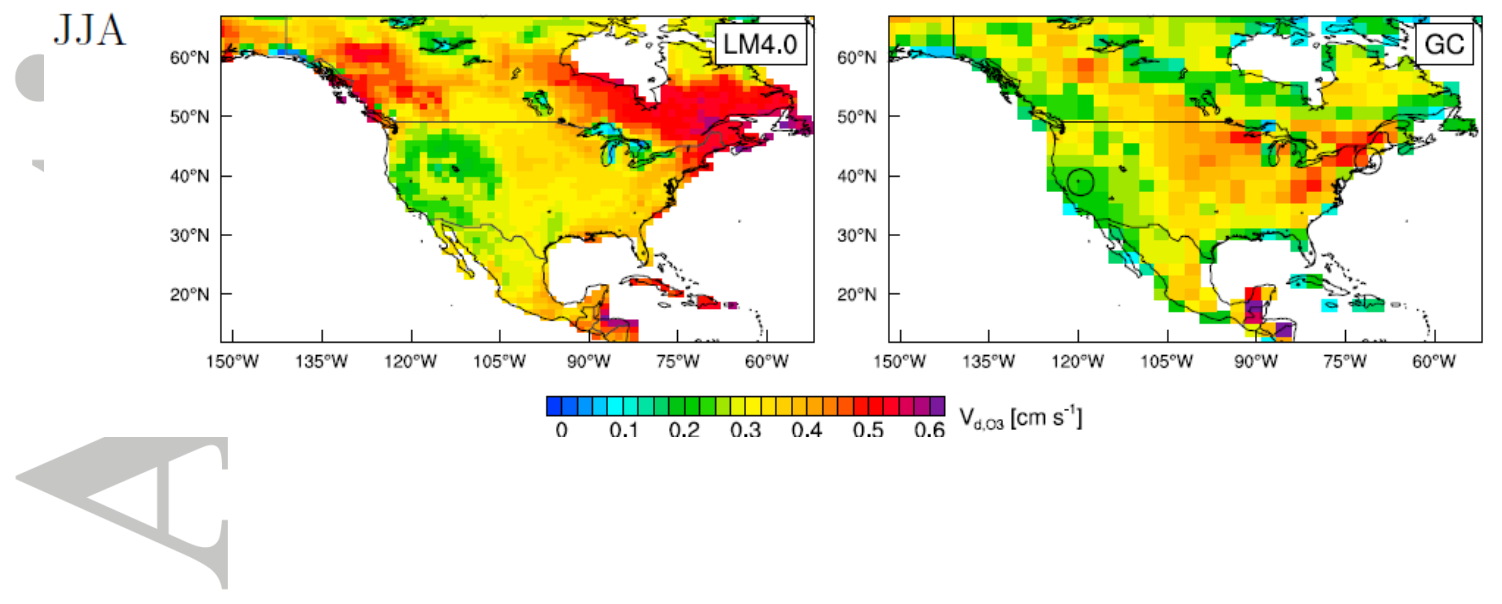

Figure 16. Same as Fig. 14 but for North America.

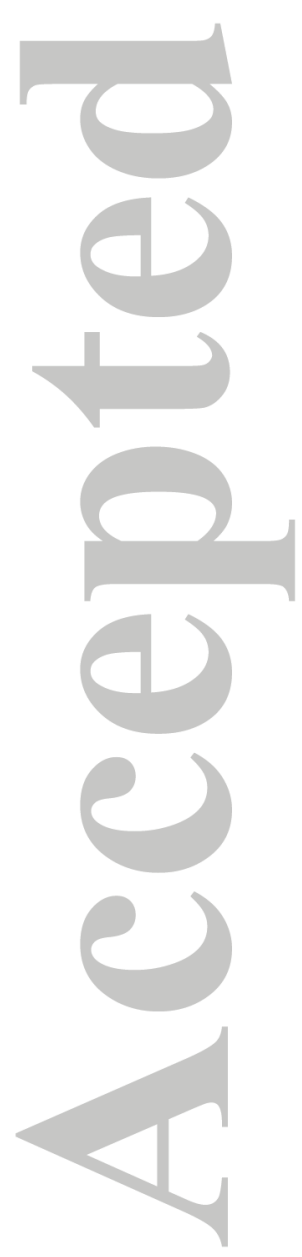



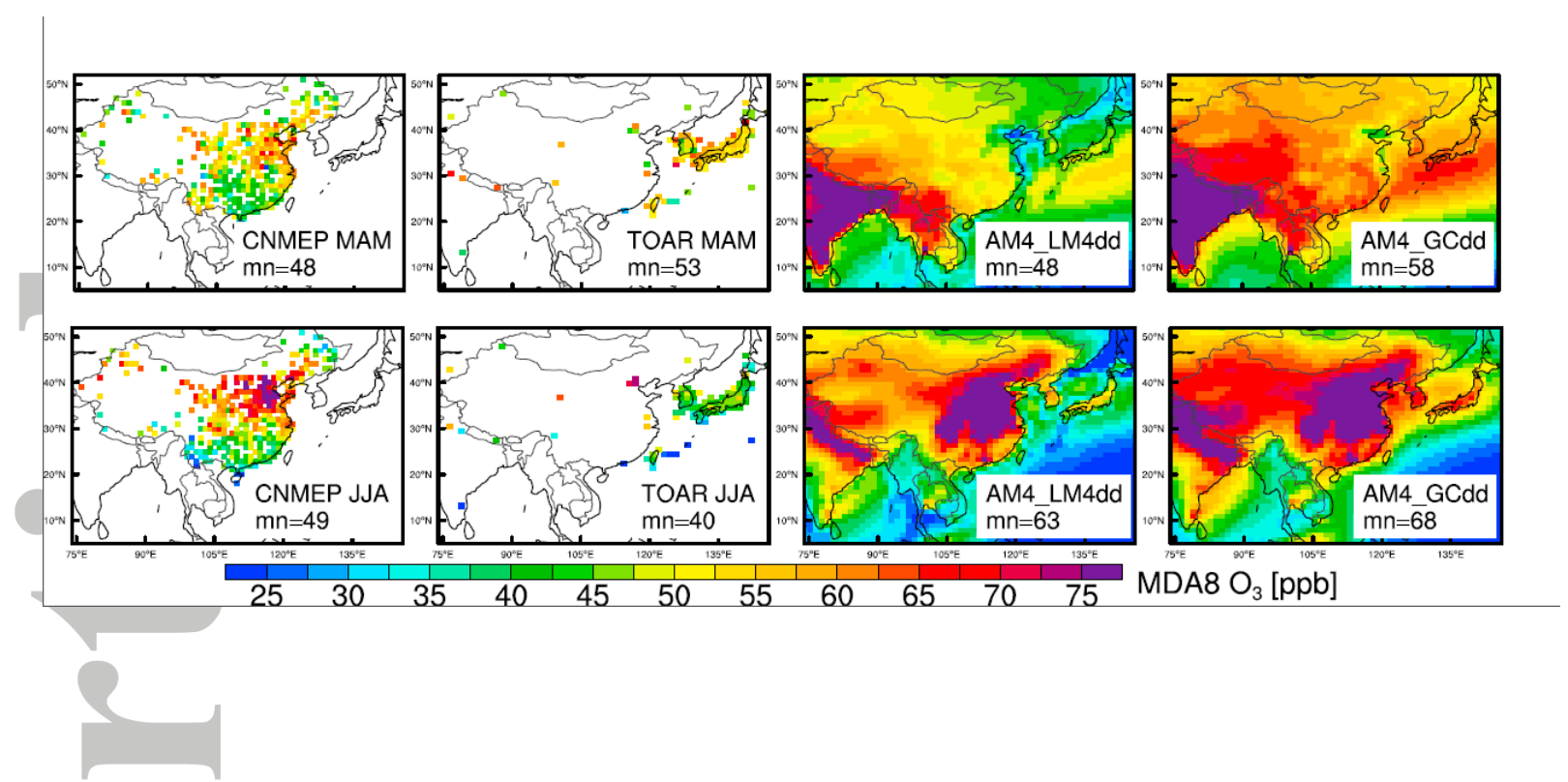

Figure 17. MAM and JJA mean surface MDA8 O3 mixing ratios over East Asia from CNMEP observations (2013-2017), TOAR observations (2005-2014) and AM4 simulations (2005-2014) with $\mathrm{Vd}, \mathrm{O} 3$ from GFDL-LM4 versus from the Wesely scheme as implemented in GEOS-Chem.

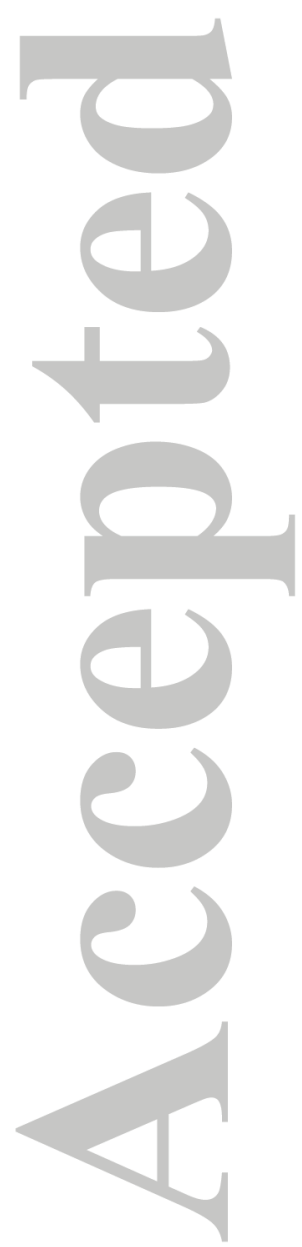




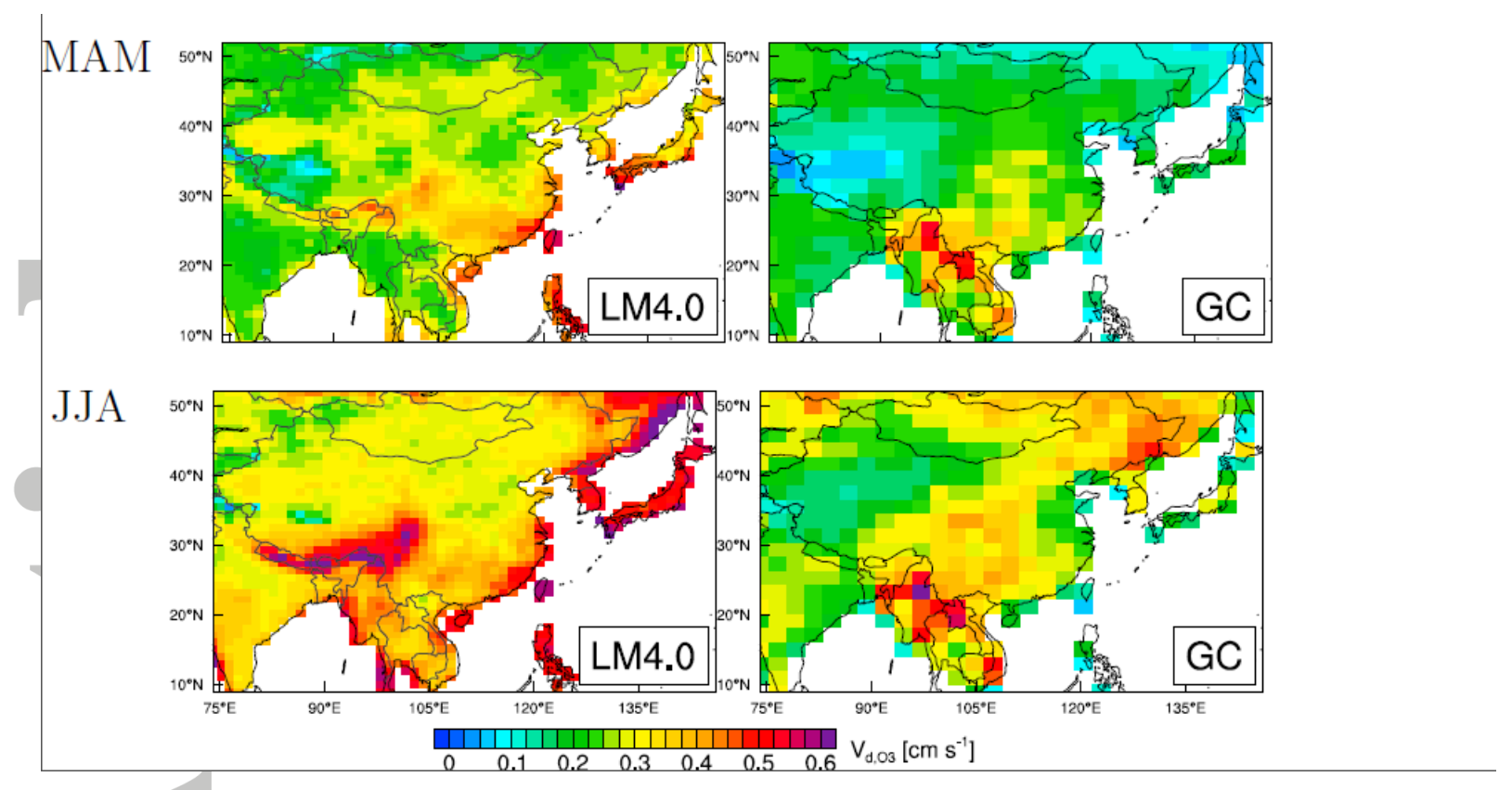

Figure 18. Same as Fig. 14 but for East Asia.

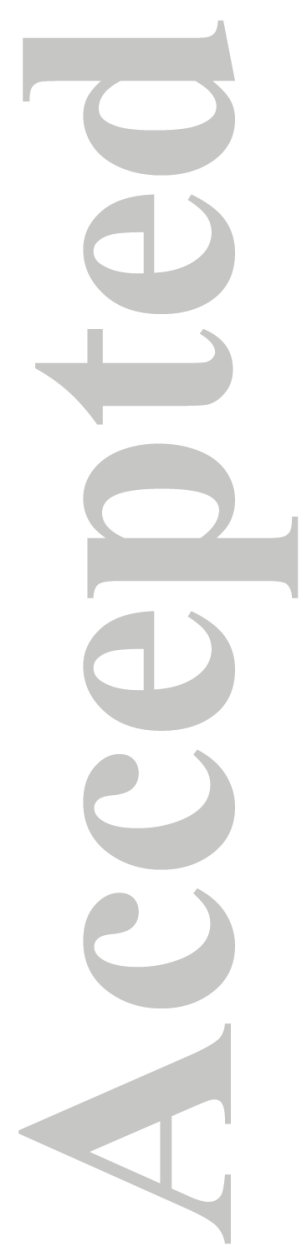

